\title{
Oleneostrovski mogilnik: Reconstructing the Social and Economic Organization of Prehistoric Foragers in Northern Russia
}

\author{
JOHN O'SHEA \\ Museum of Anthropology, University of Michigan, Ann Arbor, Michigan 48109
}

AND

MAREK ZVELEBIL

Department of Archaeology, University of Sheffield, Sheffield SIO 2TN, England

\begin{abstract}
Oleneostrovski mogilnik (Red Deer Island cemetery) in Karelia, USSR, is the largest known Mesolithic-age cemetery in the Boreal zone, containing the remains of at least $\mathbf{1 7 0}$ individual interments. An analysis of mortuary patterning, demographic structure, and regional interaction was performed in order to elucidate the nature of Boreal zone forager society during the late Mesolithic. These analyses suggest that the society which produced Oleneostrovski mogilnik was larger and more internally differentiated than previously believed, with a complex system of social differentiation that included hereditary social positions and economic ranking. It also participated in an extensive regional exchange network which moved exotic goods and raw materials over considerable distances. It is concluded that the climax of forager occupation in the Boreal zone occurred during late Mesolithic times, with a maximum density of population and maximum social complexity, and that more recent hunter-fisher-gatherer occupations represent only a pale reflection of this peak.
\end{abstract}

\section{INTRODUCTION}

A widespread problem in the study of hunter-gatherer social formations has been the inability of archaeology to move beyond the limits of the ethnographic present (cf. Wobst 1978). Despite the recognition that hunters and gatherers in the past often lived in lush environments [unlike the marginalized populations of the ethnographic record (Lee and DeVore 1968)] and evidence for dense population concentrations (Clarke 1976), most studies of Mesolithic communities still return to the entrenched concept of hunter-gatherer society as necessarily small, simple, and egalitarian. Clearly, if archaeology is to understand the true range of social 
forms which may have characterized nonmarginal hunter-gatherers, we must resort to techniques of analysis which do not rely directly on the ethnographic or historical record. There are two alternatives.

The first is to utilize models and theories from other disciplines to simulate potential hunter-gatherer adaptations. Although this provides, perhaps, the most general solution to the problem of alternative social and economic structures, the demonstration that a particular adaptation was theoretically possible is not, in itself, satisfying. It is necessary to show that the model approximates a cultural reality. Unfortunately, the testing of such models against archaeological data, required for such a demonstration, has to date been extremely limited. The second approach is to employ existing middle range archaeological theory to construct culture contexts (Taylor 1967:111-112) from suitable archaeological cases. This approach converts archaeological evidence from a site or set of sites into a form which is accessible to more direct anthropological evaluation. In this fashion, cases from the past may be combined with equivalent historical and ethnographic observation to form the basis for higher order modeling.

These alternative methods for the study of past social organization need not be viewed as antagonistic, and indeed, should be seen as complementary. The first infers general statements about social formations which can then be tested against the archaeological record. The second approach documents the complexities of a single case in the past. The value of a reconstruction so derived is highly dependent on the quality of the starting data. Yet, in instances where the archaeological record permits, this approach can provide a new and highly detailed view of past societies. The research which is presented here will utilize this second approach to analyze the unique mortuary occurrence at Oleneostrovski mogilnik. In this way we will provide a new view of Mesolithic forager society in northern Russia.

Oleneostrovski mogilnik (Red Deer Island cemetery) is the largest known Mesolithic cemetery in the Boreal zone. Excavations carried out in the 1950 s recovered 170 burials, and the total number of graves at the site has been estimated at more than 400 (Gurina 1956). Of other Mesolithic age cemeteries, only the site of Cabeco da Arruda in Portugal is of comparable size with 178 individuals (Newell, Coustandse-Westermann, and Meiklejohn 1979:148). Other Mesolithic cemeteries tend to be considerably smaller with the largest containing between 20 and 60 individuals, such as Zvejnieki in Lithuania with 60 individuals (Zagorski 1973), Vedbaek in Denmark with 23 individuals (Albrethsen and Peterson 1976), Teviec in France with 23 individuals, and Moita do Sebastiao in Portugal with more than 40 individuals (Newell, Coustandse-Westermann, and Meiklejohn 1979). Oleneostrovski, then, provides us with a unique op- 
portunity to apply techniques for social and demographic reconstruction to a Mesolithic community.

The cemetery is located in the northern section of Lake Onega, in Karelia, USSR (Fig. 1). The environment of the area, in its physical aspects and natural resources, is characteristic of the southern portion of the Boreal zone. It is marked by coniferous forests, numerous rivers and lakes, and rich aquatic resources. Pronounced seasonal variation and unpredictable fluctuation in food resources are a result of the region's essentially simple food web (Dylis and Sukhachev 1964).

The cultural sequence of southern Karelia is very similar to that of neighboring regions of Finland and northern Russia. After the retreat of the Scandinavian glacier, the area became inhabited by foragers who shared bone and stone assemblages comparable to the Suomusjärvi culture of Finland and the Kunda culture of Estonia. Fishing, sealing, hunting, and gathering formed the diverse basis of subsistence (Gurina 1956; Forsten 1972; Zvelebil 1978). Pottery, appearing at the end of the fifth millennium, was not accompanied by agriculture, as hunting and fishing remained the principal mode of subsistence for another 3000 years (Zvelebil 1978; Dolukhanov 1979).

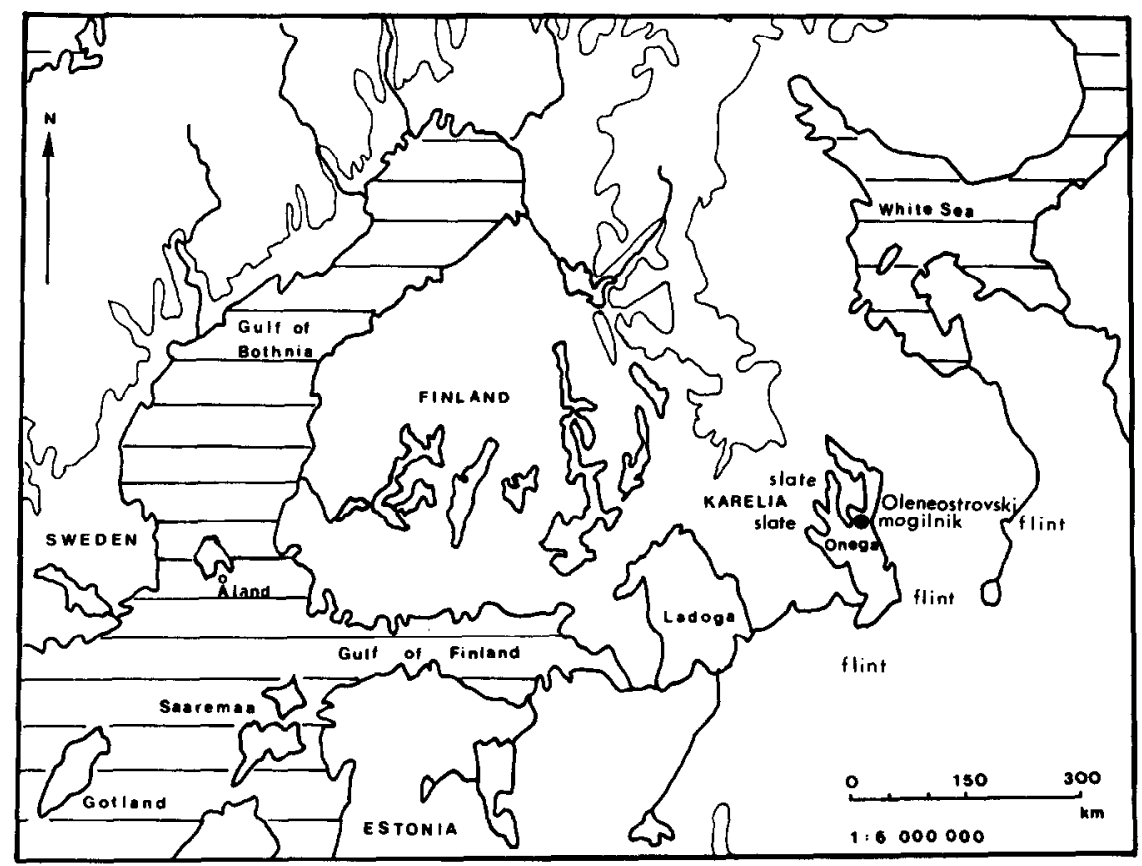

FIG. 1. Location of Oleneostrovski mogilnik. 
Within this cultural and environmental context, the existence of Oleneostrovski mogilnik is unique. The large size and the rich character of the mortuary deposits initially led to the belief that the cemetery dated to the second millennium B.C. (Ravdonikas 1940) or the second half of the third millennium (Gurina 1956). The absence of pottery among the grave goods was explained as ritual prohibition. However, strong similarities between the stylistic characteristics of the Oleneostrovski mogilnik assemblage and those of the Suomusjärvi-Kunda Mesolithic indicate that the cemetery should be dated to the prepottery Mesolithic (Pankrushev 1978). This is further supported by shoreline displacement analysis (Siiriäinen 1973). These results, applied by Pankrushev (1978) to the region of Lake Onega, date the cemetery well into the Mesolithic period on geological grounds.

The intent of this paper is to analyze the rich archaeological evidence of Oleneostrovski mogilnik in order to draw inferences about the organization of this late Mesolithic society. The impressive nature of the cemetery runs counter to the conventional view of hunter-gatherers, fueled by modern ethnographic studies. Such societies are conventionally regarded as having a relatively simple social and economic structure which is ill-equipped to dcal with social tension and subsistence shortages cxcept by dispersal (Lee and DeVore 1968; Tilley 1981). We will examine this premise in view of the Oleneostrovski finds.

The cemetery is spread over stony ground on a small island off the northern shore of Lake Onega. The area of the site has been used as a quarry and some sections of the cemetery, especially its southern portion, have been destroyed in the process (Fig. 2). Quarrying, however, did not obscure the fact that the burials are divided into two spatially distinct groups-a northern and a southern cluster. In all, 170 burials were uncovered during excavations which covered $2350 \mathrm{~m}^{2}$ (Gurina 1956). The deceased were buried $0.60-1.20 \mathrm{~m}$ below the ground surface, with a mean depth of about $1.0 \mathrm{~m}$. The majority of the graves consisted of a single burial. However in 16 cases double burials and in 3 cases triple burials were observed. In general the graves do not overlap. Where overlap does occur, the lower burial was usually left undisturbed.

Of the more than 7000 artifacts that were recovered from the burials, approximately 6000 were of bear, beaver, or elk pendants, made of perforated teeth. The remaining objects consisted of hunting implements, other tools, and a series of sculptured effigies of elk, snakes, and humans.

\section{OLENEOSTROVSKI SOCIETY—PREVIOUS INTERPRETATIONS}

According to Gurina's (1956) interpretation, Oleneostrovski mogilnik represented an acephalous, egalitarian society, devoid of any form of social 


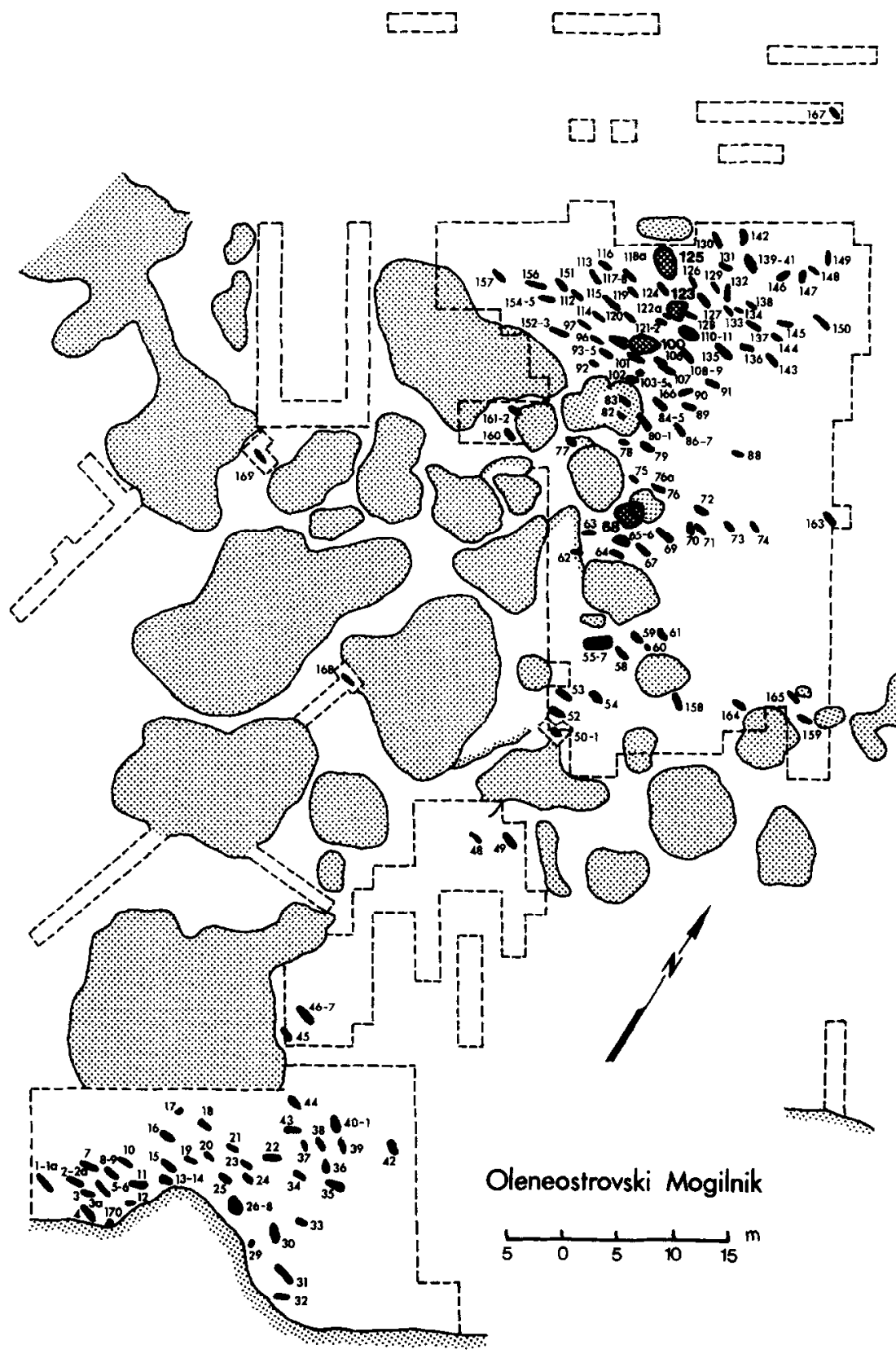

FIG. 2. Plan of the Oleneostrovski cemetery. Fine stippled areas represent ground surface irregularities, primarily depressions. Graves marked with bold numerals and stipple indicate the location of upright interments. 
ranking. Variation in the quantity of grave goods, which ranged from none in $20 \%$ of the cases to more than 400 artifacts, were explained in terms of status achieved during the individual's lifetime. Gurina compares the society at Oleneostrovski to the reindeer breeding and hunting societies of the Boreal zone, whose social organization is simple, egalitarian, and acephalous (Gurina 1956:197-199).

According to this interpretation most of the variation in the grave goods reflects the sexual distinction between male and female roles. Hunting equipment prevails in male graves, while female graves contain principally household equipment. Hunting equipment included bone and stone points, bone daggers, slate knives, harpoons, fishhooks, and quivers. Among these, bone points, fishing gear, slate knives, and quivers occur almost exclusively with males. Female graves are in general less well cquipped than malc graves. Household artifacts, flint blades, awls, polishers, piercers, and scrapers are held by Gurina to predominate in female graves. Certain forms of pendants, such as the beaver incisors and snake effigy figures, also appear to be associated more commonly with female graves.

In addition to this basic dimension, which reflects the division of labor between male and female, Gurina recognized one additional social dimension which was expressed by the occurrence of four "shaft graves." This was the only instance where individuals were acknowledged by Gurina to possess a special status (1956:236-237).

The shaft graves were constructed in a radically different way from the other graves and required a much greater expenditure of energy. They were dug vertically into the ground, so that the deceased assumed a standing posture. These graves, on the whole, seem richer than other burials, but there is a wide range of variation in the quality of items in the graves' assemblages. In Gurina's opinion, these shaft graves might have belonged to shamans or similar ritual specialists.

This explanation is consistent with the ethnographic evidence. Frequently, a different form of burial was accorded to the shaman and his kin among the recent peoples of Siberia (Czaplicka 1914). Moreover, one of the graves contained six beaver mandibles, a find which may be significant because mandibles form a part of shaman's outfits among some Siberian groups (Gurina 1956). Beaver often was held to have ritual and medicinal properties among many Boreal peoples (Eidlitz 1969).

Mortuary remains recovered at Oleneostrovski mogilnik included $\mathbf{4 2}$ sculptured or ornamented objects. Among these, the more prominent were realistic representations of elk, snake, and humans carved out of stone, wood, or bone. Such symbols are widespread in the Boreal zone, although these mortuary effigy figures are unique. Gurina discusses their significance in detail (1956:242). 
Two explanations are presented: the effigies identify different clans burying their dead side by side at Oleneostrovski; or the effigies represent benevolent deities. In the latter case, elk would be the "benefactor" of men, snake of women. Even though Gurina suggests that the situation of elk effigies with the upper part of the body indicates their function as scepters to be carried in the hand as signs of authority or clan identity, in the end she regards both hypotheses as equally plausible.

In Gurina's view, Oleneostrovski presents evidence for three basic types of social differentiation: (1) distinct male and female spheres of activity; (2) shamans; and (3) possible totemic groups. These social distinctions are seen as the basic elements structuring an essentially acephalous and egalitarian society. Such an interpretation would suggest that the society which produced Oleneostrovski was not markedly different from the reindeer breeding and hunting societies of later times.

These interpretations, and the evidence on which they are based, provide the starting point for the present analysis. This summary hardly does justice to Gurina's original work, which extends some 400 pages, nor to the careful and comprehensive detail with which the finds from Oleneostrovski are presented. Any criticism regarding previous interpretations of the Olencostrovski finds arc made with a full recognition of the debt which this study owes to Gurina's original work.

\section{RECONSTRUCTING THE SOCIAL ORGANIZATION OF OLENEOSTROVSKI SOCIETY}

Mortuary evidence is an extremely rich source of information regarding the social and economic structure of past societies. In this section we will summarize the results of a detailed analysis of the Oleneostrovski mogilnik as the basis for a tentative reconstruction of the late Mesolithic society. The following sections will then consider the demographic structure of the population and the larger social environment of the Karelian region during the late Mesolithic.

The Oleneostrovski mortuary complex was analyzed using a "dimensional" approach. This procedure was pioneered by Brown (1971) and Saxe (1970) and has been applied more recently by Braun (1979) and O'Shea $(1978 ; 1981 a)$. In essence, this procedure attempts to identify each distinct category of differentiation which is expressed in the mortuary ritual. These dimensions of mortuary treatment are then related back to categories of social differentiation which existed in the living society.

With Oleneostrovski, we first will identify the normative aspects of the burial ritual-those elements which were received by most or all members of the society. We then will discuss those aspects of the burial complex which served to differentiate subgroups within the mortuary popu- 
lation, considering, first, aspects of body treatment and placement, and, then, the distribution of grave goods. Once the main dimensions of differentiation are isolated, the size and demographic composition of each subset will be used to infer the kind of social unit which it represents. In this way a composite picture of Oleneostrovski societal organization can be constructed. Of course, alternative explanations may exist for the patterns of mortuary differentiation observed. The model we present is a parsimonious and internally consistent explanation for the patterning observed at Oleneostrovski, but we hardly would wish to imply that it is the only possible interpretation. The value of any counterexplanation would be determined, however, by its ability to better account for the very clear and consistent patterning which structures the Oleneostrovski mortuary occurrence.

The one limitation inherent in social reconstructions based on mortuary evidence is that they often are incomplete; that is, there will have been additional categories of social differentiation which will not be detected by analysis. This incompleteness may be due both to the fact that some forms of social differentiation may not be expressed through an individual's mortuary treatment, and that some aspects of mortuary symbolism frequently are undetected by archaeological analysis (O'Shea 1981a: 52). For Oleneostrovski mogilnik, therefore, the social reconstruction represents the minimum level of internal differentiation which may have existed within the late Mesolithic society.

\section{Analysis of Mortuary Treatment}

The normal mortuary treatment observed at Oleneostrovski consisted of the body being placed on its back in an extended posture. The grave typically was oblong in shape, and was excavated along an east-west axis. The body was positioned in the grave so that it faced east. After placement in the grave, the body was sprinkled with red ochre. No evidence was observed to suggest the use of any kind of coffin, nor was there evidence of special mortuary architecture.

Although these practices were by far the most common, a number of variations were observed which will serve as a starting point for our consideration of social differentiation at Oleneostrovski mogilnik. The most fundamental type of mortuary differentiation was between those who were buried at the site and those who were not. Individuals of certain age groups, particularly infants and children, were infrequently buried at Oleneostrovski. Individuals under the age of 10 years accounted for only about $7 \%$ of the mortuary population, while in natural populations the expected proportion would be anywhere from 30 to 50\% (Weiss 1973). A 
second broad level of mortuary distinction was observed in the location of graves within the cemetery, i.e., the northern and southern burial clusters (Fig. 2). Although these clusters are not equal in size (due in great part to quarry work in the area of the southern cluster), the distribution of most other classes of mortuary differentiation will be shown to crosscut this spatial boundary. These factors suggest that the spatial separation denotes a broad, bipartite division of the society.

Four individuals, all buried in the northern cluster, were accorded a special burial treatment. These individuals were interred in a vertical shaft-type grave, which consisted of a funnel-shaped shaft, wider at ground level than at the base, and reaching a depth of 1.3 to $1.8 \mathrm{~m}$. One side of the shaft was vertical, and the other sloped at an angle of about $45^{\circ}$. The deceased was placed standing against the sloping side and the intervening space between the deceased and the vertical side was filled with stone. These shaft burials represent the most elaborate and effortconsuming funerary treatment practiced at Oleneostrovski mogilnik. In addition, all four of these individuals were positioned so that they faced in a westerly, rather than easterly direction. These were the only examples of west-faced burials at the site. Of these individuals, two were male, one an adult and the other a mature individual; and two were female, one a young adult and the other a mature person. The abnormal burial posture, the amount of effort expended, and the reversed orientation clearly mark these individuals as special persons. It is interesting to note that this social status was open to individuals of either sex.

The final class of burial treatment observed at Oleneostrovski was multiple interment. In all, 18 intentional multiple burials were observed (as opposed to accidentally superimposed graves). Of these, adult males were found in 10 , adult females in 9 , and subadults in 10 . The number of subadults is significant considering that only 14 subadults were encountered at Oleneostrovski. No pattern of spatial preference was observed in the occurrence of multiple interments nor did there seem to be any consistent pattern in their occurrence, except for subadults. For adults, multiple interment probably represented an expedient used when two relatives died at about the same time. For those subadults who were buried at Oleneostrovski, multiple interment seems to have been the norm.

In terms of these differential treatments it seems that in addition to the normative funerary treatment afforded most members of Oleneostrovski society, three further social dimensions were symbolized: the special status of infants and children; the two-part division of the society expressed through the two burial areas; and the special status associated with shaft burials. The further definition of these social dimensions will be explored in light of artifact occurrences at Oleneostrovski mogilnik. 
Analysis of Grave Offerings

The analysis of grave goods at Oleneostrovski started with the definition of a 31-element descriptive typology. This typology was primarily sensitive to the functional category of the object and to its raw material. The artifacts fell into three basic classes: implements, ornaments, and unworked animal bone.

Two distinct patterns of artifact abundance were observed. Some types exhibited a marked variation in their abundance from one grave to the next, while others occurred in relatively uniform quantities. For this reason, types were further classified as quantitative or discrete types, with the assumption that discrete types would express meaning through simple occurrence, while quantitative types would communicate additional information through their relative abundances. The 31 types and their distributional characteristics are presented in Table 1.

As a first step in the analysis, the occurrence of each artifact type was evaluated to identify those artifacts which exhibited a regular association with individuals of a particular age or sex, or a distribution restricted to one of the two burial areas. Associations were measured using Kendall's $\tau$ (Siegel 1956), and a probability less than 0.10 was considered significant. Artifacts exhibiting significant associations are also listed in Table 1. A total of eight types exhibited a significant association by gender. Seven types, all implements, including bone points, bone harpoons, slate knives, slate daggers, stone axe/adzes, bone pins, and small flakes, were regularly associated with males, while carved beaver incisor ornaments occurred significantly more frequently with females. What is surprising in these findings is the absence of a parallel set of female implements.

Although the small number of subadults represented at Oleneostrovski precludes the realistic testing of age associations, it appears that most of the implements observed as burial offerings were limited to adults.

Two artifact types exhibited a positive association with one of the two burial areas. Elk effigy figures were restricted in their spatial distribution to the northern cluster. The snake and human effigies were encountered in both areas, although they were more numerous in the south. This distribution supports the earlier assertion that a binary social division was symbolized through the use of the two burial areas. Elk incisor pendants were the only other type to exhibit a significant spatial distribution. They were not associated in the number of graves which contained elk incisor pendants, but rather in the quantity of these pendants within each grave. Graves in the northern cluster contained significantly greater quantities of these pendants than did the graves of the southern cluster. No other artifact type showed a significant association with one or the other burial area, either in its simple incidence or in it abundance. 
TABLE 1

Oleneostrovski mogilnik-ArTifaCt Type Frequency and Distribution

\begin{tabular}{|c|c|c|c|c|}
\hline Artifact type & $\begin{array}{l}\text { Number of } \\
\text { occurrences }\end{array}$ & $\begin{array}{l}\text { Abundance } \\
\text { distribution }\end{array}$ & $\begin{array}{l}\text { Significant } \\
\text { association }\end{array}$ & $\begin{array}{l}\text { Significant } \\
\text { spatial } \\
\text { association }\end{array}$ \\
\hline Bone point & 48 & Quantitative & Males & \\
\hline Stone point & 20 & Quantitative & & \\
\hline Bone harpoon & 3 & Discrete & Males & \\
\hline Slate knife & 29 & Quantitative & Males & \\
\hline Slate dagger & 6 & Discrete & Males & \\
\hline Flint knife & 13 & Discrete & & \\
\hline Small blade & 14 & Quantitative & & \\
\hline Stone axe/adze & 4 & Discrete & Males & \\
\hline Stone polisher & 6 & Discrete & & \\
\hline Bone polisher & 8 & Discrete & & \\
\hline Bone awl & 11 & Discrete & & \\
\hline Bone pin & 3 & Discrete & Males & \\
\hline Fishhook & 3 & Discrete & & \\
\hline Small flakes & 15 & Quantitative & Males & \\
\hline Pebble implements & 12 & Discrete & & \\
\hline Bear tusk & 49 & Quantitative & & \\
\hline Elk incisor & 83 & Quantitative & & $+a$ \\
\hline Beaver incisor & 69 & Quantitative & Females & \\
\hline Stone/bone pendant & 20 & Quantitative & & \\
\hline Orn. bone segments & 5 & Discrete & & \\
\hline Snake effigy & 2 & Discrete & & \\
\hline Elk effigy & 6 & Discrete & & + \\
\hline Human effigy & 3 & Discrete & & \\
\hline Bear bone & 21 & & & \\
\hline Canid bone & 3 & & & \\
\hline Bird bone & 7 & & & \\
\hline Beaver bone & 15 & & & \\
\hline Reindeer bone & 5 & & & \\
\hline Elk bone & 5 & & & \\
\hline Other bone & 6 & & & \\
\hline Red pigment & 155 & & & \\
\hline
\end{tabular}

a Significant in abundance distribution only.

To examine the structure of artifact usage at Oleneostrovski further, the artifact occurrence data were computerized and subjected to multivariate statistical analysis. Since the detailed discussion of these tests is beyond the scope of this paper, we shall concentrate on one of these tests, monothetic divisive cluster analysis, as representative of the multivariate findings.

Monothetic divisive cluster analysis is a technique which partitions a population so as to maximize the dissimilarity between groups on the 
basis of the presence or absence of a given attribute (Everitt 1974:20). The method used here, information analysis, employs an information measure to determine the dissimilarity between groups (Sneath and Sokal 1973:241). This type of cluster analysis has been used in archaeological studies of mortuary practices with considerable success (cf. Peebles 1972; Tainter 1975).

The present application employed procedure Divide from the Clustan package (version IC: Wishart 1978) as implemented at the University of Cambridge computer facility. The analysis incorporated all 163 undisturbed grave assemblages from Oleneostrovski and a presence/absence coding for 31 artifact types. The analysis was run through seven divisions, resulting in eight final clusters. These divisions are presented in the form of a dendrogram in Fig. 3, with accompanying cluster diagnostics in Table 2.

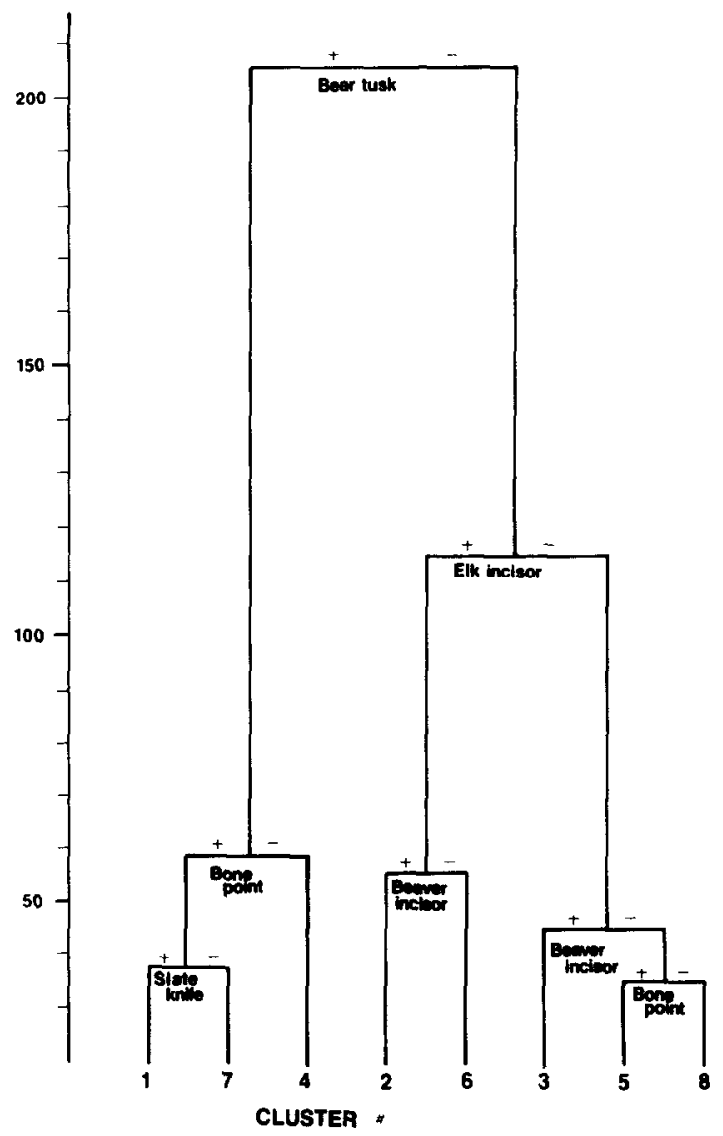

FIg. 3. Dendogram produced by monothetic divisive culture analysis of the Oleneostrovski mogilnik burials. Cluster similarity based on the information statistic. 
The initial division was made on the presence or absence of bear tusk pendants. The graves with bear tusk pendants were further divided into groups: without bone points (cluster 4); graves with tusks and bone points but without slate knives (cluster 7); and those which had all three of these types (cluster 1). On the right half of the dendogram, graves were divided into groups based on the presence first of elk incisor pendants, and then on beaver incisor pendants: cluster 2 having both types, cluster 6 having elk incisors but not beaver, and cluster 3 having beaver incisors but no elk. The final two clusters were composed of graves containing none of the three pendant types, and were themselves differentiated by the occurrence of bone points: cluster 5 with bone points, cluster 8 without.

After these eight clusters were derived, they were first tested to determine whether they had partitioned the mortuary population into specific age or sex groups or into arcally discretc groups. Only one cluster exhibited a significant association by sex, that being cluster 5 , graves with only bone points. This cluster exhibited a marked association with males $\left(\chi^{2}=4.24, p<0.05\right)$. This is not particularly surprising, since the overall occurrence of bone points exhibited a significant association with males. What is surprising is that the two other clusters which contain bone points, clusters 1 and 7 , did not exhibit a statistically significant skewing toward males, although the majority of individuals in each of these clusters were male. This seems to sugget that the role of bone points as a mortuary symbol varied depending on whether the object occurred by itself or in combination with other symbols. The importance of this finding will be discussed later.

Tests were also performed to assess the spatial occurrence of the eight burial clusters, but none showed significant preference for one or the other of the burial areas.

Although there were only a few subadults present in the cemetery, some pattern regarding age statuses can be discerned from the cluster analysis. Subadults were absent from only two of the eight clusters, clusters 1 and 5. Cluster 5, those graves containing solely bone points, seems to reflect a male-restricted status, which was limited to adult or mature males. Cluster 1 , by contrast, contains both males and females, and is composed of those graves with the greatest quantity of grave goods. The relatively small number of individuals in this cluster, and the absence of subadults from it, may suggest its representation of an elevated social standing within the population, and one requiring adult status for membership.

Looking at the results of this cluster analysis from an anthropological perspective, several aspects of Oleneostrovski mortuary symbolism can be recognized. Perhaps most interesting is the structure it reveals in the occurrence of pierced animal teeth. The first cluster division separates 
TABLE 2

Oleneostrovski mogilnik-Monothetic Division Cluster Diagnostics

\begin{tabular}{|c|c|c|c|c|c|c|c|c|c|}
\hline \multirow[b]{2}{*}{ Artifact type } & \multicolumn{9}{|c|}{ Diagnostic cluster } \\
\hline & 1 & 2 & 3 & 4 & 5 & 6 & 7 & 8 & Total \\
\hline Bone point & 14 & 5 & 4 & 0 & 11 & 6 & 8 & 0 & 48 \\
\hline Stone point & 8 & 4 & 1 & 5 & 0 & 0 & 2 & 0 & 20 \\
\hline Bone harpoon & 3 & 0 & 0 & 0 & 0 & 0 & 0 & 0 & 3 \\
\hline Slate knife & 14 & 2 & 1 & 12 & 0 & 0 & 0 & 0 & 29 \\
\hline Slate dagger & 3 & 1 & 0 & 0 & 0 & 1 & 0 & 1 & 6 \\
\hline Flint knife & 4 & 0 & 0 & 4 & 0 & 2 & 1 & 2 & 13 \\
\hline Sm. blade & 7 & 1 & 0 & 3 & 0 & 0 & 2 & 1 & 14 \\
\hline Axe/adze & 0 & 0 & 2 & 2 & 0 & 0 & 0 & 0 & 4 \\
\hline Stone polisher & 1 & 1 & 1 & 1 & 0 & 1 & 1 & 0 & 6 \\
\hline Bone polisher & 2 & 0 & 1 & 2 & 0 & 0 & 1 & 2 & 8 \\
\hline Bone awl & 1 & 1 & 2 & 3 & 1 & 1 & 1 & 0 & 11 \\
\hline Bone pin & 0 & 2 & 0 & 1 & 0 & 0 & 0 & 0 & 3 \\
\hline Fishhook & 1 & 1 & 0 & 1 & 0 & 0 & 0 & 0 & 3 \\
\hline Flakes & 5 & 3 & 1 & 2 & 1 & 3 & 0 & 0 & 15 \\
\hline Modified pebble & 1 & 1 & 2 & 4 & 0 & 1 & 3 & 0 & 12 \\
\hline Bear tusk & 14 & 0 & 0 & 27 & 0 & 0 & 8 & 0 & 49 \\
\hline Elk incisor & 9 & 21 & 0 & 23 & 0 & 23 & 7 & 0 & 83 \\
\hline Beaver incisor & 9 & 21 & 15 & 18 & 0 & 0 & 6 & 0 & 69 \\
\hline Stone/bone pendant & 7 & 6 & 1 & 2 & 0 & 2 & 2 & 0 & 20 \\
\hline Ornamental bone seg. & 1 & 0 & 0 & 3 & 0 & 0 & 0 & 1 & 5 \\
\hline Snake effigy & 0 & 2 & 0 & 0 & 0 & 0 & 0 & 0 & 2 \\
\hline Elk effigy & 0 & 1 & 1 & 1 & 0 & 1 & 1 & 1 & 6 \\
\hline Human effigy & 0 & 1 & 0 & 1 & 0 & 0 & 0 & 1 & 3 \\
\hline Bear bone & 3 & 3 & 2 & 7 & 0 & 2 & 1 & 3 & 21 \\
\hline Canid bone & 0 & 1 & 0 & 0 & 0 & 1 & 1 & 0 & 3 \\
\hline Bird bone & 0 & 1 & 0 & 1 & 0 & 2 & 3 & 0 & 7 \\
\hline Beaver bone & 0 & 4 & 1 & 4 & 0 & 4 & 2 & 0 & 15 \\
\hline Reindeer bone & 0 & 1 & 0 & 0 & 1 & 2 & 1 & 0 & 5 \\
\hline Elk bone & 1 & 0 & 1 & 2 & $\mathbf{0}$ & 0 & 1 & 0 & 5 \\
\hline Other bone & 0 & 2 & 0 & 2 & 0 & 0 & 2 & 0 & 6 \\
\hline Ochre & 14 & 19 & 14 & 25 & 10 & 21 & 8 & 44 & 155 \\
\hline \multicolumn{10}{|l|}{ Sex and age } \\
\hline Males & 7 & 4 & 4 & 11 & 7 & 9 & 2 & 11 & \\
\hline Females & 1 & 8 & 7 & 9 & 0 & 5 & 3 & 11 & \\
\hline Adult & 8 & 12 & 11 & 18 & 7 & 14 & 4 & 23 & \\
\hline Subadult & 0 & 1 & 2 & 4 & 0 & 2 & 1 & 5 & \\
\hline $\begin{array}{l}\text { Total No. of graves } \\
\text { in cluster }\end{array}$ & 14 & 21 & 15 & 27 & 11 & 23 & 8 & 44 & \\
\hline
\end{tabular}

Table 2 continued on next page. 
graves with and without bear tooth pendants. Graves with greater quantities of grave goods and those which contain most of the "expensive" items, such as slate knives and daggers, are grouped together on the left half of the dendrogram. In a similar fashion, graves which lack bear teeth are divided by the presence or absence of elk incisor pendants, a distinction which again distinguishes graves with more and less grave goods. This pattern of occurrence suggests a value ranking of these pendants: bear tooth pendants having the highest value, and elk and beaver having a lesser value. Using this as a standard, it is possible to rank all of the graves in the cemetery according to the combination of pendants in their grave assemblages. This ranking scale corresponds very closely with the occurrence of other grave artifacts, and seems to be indicative of some form of achieved wealth. The demographic and social implications of this conclusion will be discussed below.

A second element of the mortuary symbolism relates to the occurrence of prestige goods. Objects such as slate knives and daggers have long been viewed by archaeologists as exotic or prestige goods. The occurrence of these objects at Oleneostrovski confirms this view. The artifacts tend to have a limited distribution (18\% of the population) and to occur in uniform quantities, suggesting their primary function as social markers. In addition, these goods usually occur only in male graves and in grave assemblages classified as wealthy on the basis of their pendant composition. The importance of slate in the regional exchange network may explain the use of slate implements as prestige indicators. This possibility will be discussed later.

The distribution of prestige goods highlights another aspect of the mortuary symbolism. A small number of females have grave assemblages that contain prestige objects which normally are male-restricted, as in clusters 1 and 7 . In each case these are very wealthy females based on their

Grave Numbers in EAch Cluster

\begin{tabular}{|c|c|c|}
\hline $\begin{array}{l}\text { Cluster } \\
\text { number }\end{array}$ & $\begin{array}{l}\text { Cluster } \\
\text { size }\end{array}$ & Grave identification no. \\
\hline 1 & 14 & $21,32,38,46,48,62,74,86,101,108,109,115,119,136$ \\
\hline 2 & 21 & $\begin{array}{l}13,18,25,37,41,56,58,59,60,70,82,87,98,107,110,118,125,128, \\
130,145,155\end{array}$ \\
\hline 3 & 15 & $15,49,73,79,83,88,106,111,122,123,137,142,146,148,151$ \\
\hline 4 & 27 & $\begin{array}{l}2,5,6,8,9,26,57,67,68,71,76,96,103,104,114,117.120,121,124 \\
131,134,135,139,152,158,159,162\end{array}$ \\
\hline 5 & 11 & $11,28,44,50,52,55,72,91,105,143,160$ \\
\hline 6 & 23 & $\begin{array}{l}1.14,16,22,23,30,31,51,54,66,75,81,93,97,100,102,118,126,133 \\
138,140,141,150\end{array}$ \\
\hline 7 & 8 & $4,27,33,47,65,69,112,116$ \\
\hline 8 & 44 & $\begin{array}{l}1,3,7,10,12,19,24,29,34,35,36,39,40,42,43,45,53,61,63,64,76 \\
78,80,84,85,89,90,92,94,95,99,113,123,127,129,132,144,153 \\
156,157,161,163,164,165\end{array}$ \\
\hline
\end{tabular}


pendants. It was noted previously that females lack a set of mortuary goods which are equivalent to the numerous male-restricted artifacts. These results may suggest that females of high or special social standing were marked by burial with male-restricted symbols, i.e., by the intentional breakage of a normative rule governing the occurrence of social markers. The relatively rare incidence of this special usage $(9 \%$ of the female population) emphasizes the uniqueness of the females who do receive this treatment. It also emphasizes the asymmetrical symbolic definition of male and female statuses in the Oleneostrovski mortuary treatment.

\section{Interpretation of Results}

These results summarize the patterning visible at Oleneostrovski mogilnik and the prime vectors for the expression of mortuary differentiation. The global character of mortuary differentiation at Oleneostrovski and the invariant usage of specific symbolic markers throughout the site make it very unlikely that the mortuary occurrence is the result of more than a single use episode. Nowhere do we observe the symbolic discontinuities which ordinarily are associated with multicomponent cemeteries. Later in this study we will offer specific estimates for the length of time during which the site was in use.

Having identified the principal dimensions of mortuary differentiation at Oleneostrovski mogilnik, we must now interpret this patterning in social terms, and integrate these varied aspects of the social organization into a coherent model of Oleneostrovski society.

The patterns of mortuary differentiation observed at Oleneostrovski reflect the operation of at least seven independent social dimensions. These dimensions express band membership, age, sex, personal wealth, and an additional three specialized social positions of ritual significance.

Based on these analyses, we conclude that two distinct but equivalent social units made use of Oleneostrovski mogilnik. Group membership was expressed in the mortuary ritual by burial in one of two discrete areas. The validity of this distinction is further supported by the tendency for each of the effigy forms to predominate in one of the burial areas: elk in the north, snake and human figures in the south. There is no difference in the representation of age or sex categories in either cluster, strengthening the argument that these indeed do reflect a horizontal type of social distinction.

Although these factors highlight the distinctiveness of the two groups, the fact that the other dimensions of mortuary differentiation crosscut this spatial boundary suggests that the two groups were closely related. A comparable recent example can be found in the burial practices of the Khantsy of western Siberia (Balzer 1980). Here effigy symbols, such as ravens, falcons, and snakes, were placed with selected female graves to 
designate clan membership. Although several clans made use of the same burial area, each clan placed their dead in a spatially discrete cluster. Archaeologically, this would result in a distribution similar to that at Oleneostrovski mogilnik.

At present, however, the precise anthropological equivalent of these social subdivisions cannot be determined. Depending on the size and residential structure of the Oleneostrovski population, they might represent clans or lineages; or they might represent small, autonomous bands. Without complementary evidence on Oleneostrovski settlement structure, it is not possible to distinguish between these alternatives.

Distinctions based on sex were expressed primarily by the kinds of articles placed in the grave with the deceased. A total of seven types were limited in their distribution to adult males. These artifacts included implements which would have been employed in male subsistence activities, such as bone points, bone harpoons, axe/adze, flakes, and slate knives and daggers. These last two artifacts may also have had a larger importance as exotic goods and indicators of high social standing. Females, on the other hand, were not observed to possess a comparable set of implements. Indeed, only one type, beaver incisors, evidenced a strong association with females. The lack of symmetry between males and females in terms of the grave assemblages is somewhat surprising in terms of the assumption of essential symmetry (Godelier 1977) among simple societies, and argues instead that male-based activities were at least perceived as being of higher value to the society than female activities. Yet, this having been said, what is perhaps most important to understanding Oleneostrovski social organization and the relative roles of men and women within it is that, with but one exception, females could hold any of the special status positions recognized in the funerary treatment. So, although more symbolic effort was expended in the definition of male activities, females were active participants in the ritual and political life of the society.

The next general social dimension recognized at Oleneostrovski mogilnik was an individual's economic standing within the society, and as such will be termed "wealth" for simplicity. Wealth was expressed through the type and quantity of pierced animal tooth pendants interred with the deceased. Although teeth presumably were available from a large number of both terrestrial and aquatic species, the teeth from only three species were utilized: bear tusks, elk incisors, and carved beaver incisors.

The tooth pendants exhibited a clear hierarchical order relative to each other, which corresponded with the number and variety of other goods which were also found in the grave. Graves containing bear tusks (either alone or in combination with other bead types) were the most wealthy, then graves containing either elk or beaver incisors, and finally those graves with no pendants. Knowledge of an individual's rank, based on 

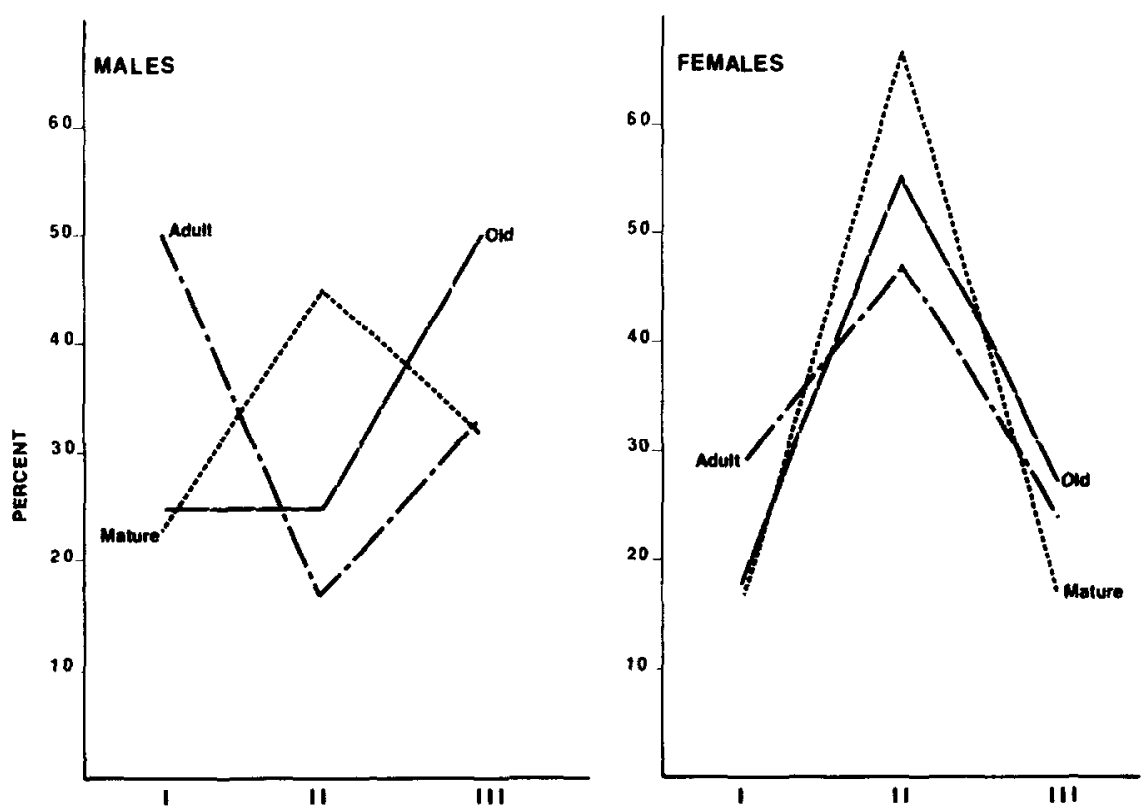

WEALTH LEVEL

FIG. 4. Distribution of wealth categuries by age and sex. Class I-bear tusks; Class IIelk or beaver incisors; Class III-no tooth pendants.

his animal teeth, rendered the occurrence of a large number of other grave artifacts predictable, as they seemed to function as embellishment to the basic ordering of individuals on this dimension.

Wealth, as measured on this dimension, does not appear to have been a stable commodity which an individual slowly accumulated through life, but rather it seems that individuals in the prime of their life possessed the greatest quantities, while the young and the old exhibited consistently lower quantities. Figure 4 presents the percentage of each age category by sex in the three wealth strata. Among adult males we see the highest proportion of type I wealth (with bear tusks), with lower proportions of type II and III assemblages. Among mature males, the proportion of type I graves drops sharply, and type II assemblages (those with elk or beaver pendants) exhibit the highest overall proportion. Finally, among old males, type III assemblages dominate, while both type I and II grave assemblages occur in low proportions. Among adult, mature, and old females, we see a general distribution of grave assemblages emphasizing type II wealth levels similar to the pattern observed for mature males. Again, however, among females the older the individual is, the less likely that she will possess a type I assemblage.

These differences in the distribution of wealth indicators provide us 
with information on two aspects of the Oleneostrovski economic system. First, it appears that the ability to procure and maintain wealth among males was linked with the individual's physical abilities, and that as an individual's vigor decreased, he was able to procure and maintain progressively less wealth. Such a system might very likely be linked to food procurement itself, perhaps indicating an individual's ability to procure food in quantities sufficient to permit the "giving away" of food within the community. Indeed a similar system has been observed among the Nivkhi (Black 1972), where prestige goods served as a backup resource for the owner and his kin. In case of need these goods were exchanged for food or other provisions indispensable in the socioeconomic system of these Siberian people. The distinct pattern observed among females seems to suggest that males, rather than females, were directly tied to the wealth-generating system, since females exhibited considerably less age-dependent change in wealth standing throughout their life. This might indicate that female wealth markers were obtained through either affinal or consanguinal ties to males.

The remaining three social dimensions mark a relatively limited number of individuals who held special status positions within Oleneostrovski society.

The first of these special dimensions included a series of four individuals, those interred in a standing posture in a vertical shaft grave. Both males and females could occupy this social status, and it seemed to have a positive correlation with an individual's wealth, as three of the four individuals possessed grave assemblages of the highest wealth level. These observations are all consistent with Gurnia's interpretation that they are the graves of shamans.

A set of nine graves, two in the southern cluster and seven in the northern group exhibited the second special dimension. These individuals were interred with carved effigy figures. This social status could be held by adults of either sex and was most common among older individuals. The social status also seems to have been independent of personal wealth, as all three wealth strata were represented among the nine individuals. The apparent relationship between the effigy figures and the spatially separate bands would suggest that these individuals held some manner of office or position related to the central ritual identity of the bands. The range of ages among office holders (from adolescent to very old) and the independence from personal wealth may also suggest an ascriptive or hereditary component to the social position.

The final dimension which can be recognized at Oleneostrovski mogilnik was seen in a series of 11 individuals that were interred with bone projectile points as their sole grave good. All of these individuals seem to have been males, and at least half of them were mature or old in age. These graves are unusual in that an implement is found to occur without 
at least some variety of animal teeth or other grave goods. This may indicate that these individuals occupied a specialized male status position which was either qualitatively different in its burial treatment, or one which prohibited the accumulation of personal wealth. Since the bone point was employed as a hunting implement, and because there was a close association of the wealth symbols with food procurement, these individuals may have possessed special abilities or responsibilities connected with the hunt which prevented their participation in wealth acquisition activities. This conclusion clearly is speculative, but it is consistent with common ethnographic patterns of social symbolism and prohibition.

If we attempt to integrate these various social dimensions into a single social system, we observe a society which is perhaps more complex than the average hunter-gatherer band, but one which is consistent with the operation of a food collecting society within the Boreal zone. Although three distinct levels of wealth can be seen to have existed in Oleneostrovski society, the overall distribution of wealth was fairly continuous. We do not observe marked differences in wealth between the two bands, nor is there evidence for the transmission of wealth across generations. Crosscutting these band and wcalth distinctions, were a set of normative rules of mortuary treatment, common age and sex distinctions, and a series of specialized statuses reflecting social positions significant to the ritual life of the society.

These results, while not diametrically opposed to earlier interpretations, argue for a society which is far more complex and internally differentiated than that envisioned by Gurina (1956). Gurina's model supposed a relatively simple, small-scaled society whose mortuary practices symbolized primarily the essential division of roles between male and female (Engels 1884), Our analysis suggests that such a simple explanation is insufficient. These results indicate that the mortuary treatment was organized as a complex ritual system carrying a wide range of social and economic information. The existence of such a system of social statuses, some hereditary, and the institutionalized economic structure which pervades the mortuary symbolism argue for a society organized at a level of complexity beyond that of most modern hunter-gatherer societies.

\section{OLENEOSTROVSKI MOGILNIK IN THE LIGHT OF ETHNOGRAPHIC ANALOGY}

Although we have argued that the burial practices at Oleneostrovski mogilnik are complex by Boreal standards, such complexity is not unprecedented in the ethnographic literature of Boreal zone peoples. Despite the often assumed simplicity of Boreal hunter-fisher-gatherer societies, a wide range of mortuary practices are known. 
It is true, of course, that the mortuary practices among many of the recent peoples of Siberia are notably uniform and unceremonious. The Kamchadal, for example, throw the corpses out to be eaten by dogs. The Tungus sew their dead in reindeer skins and hang them in trees. The Yukagir place the dead upon wooden piles and distribute the bones of shamans among the relatives (Czaplicka 1914; Jochelson 1905-1908). Fascinating as these may be, such mortuary practices leave little evidence to be studied by archaeologists.

Further, in many recent ethnographic cases the dead were cremated. The Koryak and the Nivkhi are good examples. Despite a strong ancestral cult (Jochelson 1905-1908; Magnarella 1972), the Koryak burial rite is relatively simple and involves cremation and a sacrifice of reindeer. Before cremation, the body is dressed in an elaborate garment and personal belongings are placed with the deceased. Then the body is burned and several reindeer are sacrificed as offerings. While the range of goods that would have been recovered in an archaeological context is similar but less elaborate than that of Oleneostrovski mogilnik, there does not seem to be the variation in mortuary offerings that has been noted at Oleneostrovski. The Koryak society is described as egalitarian and acephalous, with positions of leadership being only temporary (Jochelson 1905; Mangarella 1972).

Cremation is also practiced by the Nivkhi. Yet the greater variation in personal wealth among the Nivkhi does seem to be reflected in the greater complexity of their burial rites. Unfortunately for the archaeologist, objects reflecting personal wealth and status were most often destroyed during cremation (Black 1972).

Personal wealth could not be transformed into an inheritable office or permanent status, however. A man's prestige died with him (Black 1972). This was at least partly because material success was related inseparably to man's good relations with the supernatural; and good fortune was given to an individual; it was not inheritable or transferable. As pointed out earlier, this was partly due to the fact that personal wealth did not absolutely belong to one person. In case of lineage need, prestige goods could be claimed and the owner was obliged to place these goods at the disposal of his agnates. In this way valuables served as a backup resource not only for the owner, but for his entire lineage. Consequently, the social organization among the Nivkhi remained acephalous and egalitarian, governed by the principle of lineage solidarity and respect for age (Black 1972).

There are societies, however, where differences in personal wealth and prestige were more marked than among the Koryaks and the Nivkhi. As examples we may consider the Reindeer Chukchi and Maritime Chukchi. Differences in wealth among the Reindeer Chukchi were expressed in the number of reindeer each head of family possessed. This ranged from no 
deer at all to as many as $\mathbf{5 0 0 0}$ deer, an ecologically imposed limit on herd size (Leeds 1965). These differences were expressed in the personal lifestyle and status of the herd owner during his lifetime.

Yet despite the apparent economic potential for the rise of a stratified society, there was no development toward permanent chieftainship or established social ranking. Although there is an ecological optimum at which reindeer herds could be maintained-and the Chukchi indicate an awareness of this-(Bogoraz 1904-1909; Leeds 1965), the social institutions and ideology of the people were adapted toward maximizing herd size. Once a large herd size was attained, there was no economical way of controlling it or of disposing of the excess deer. This lack of social control over herd size and the lack of market for the excess deer led to two consequences, both of which rendered deer herds an unstable economic base for the evolution of a ranked social system. Reindeer herds were frequently reduced catastrophically through famine or disease, or the "rich man," unable to control his large herd, had to divide it among his kin without remuneration.

The Reindeer Chukchi disposed of their dead through cremation or exposure. The deceased were left with piles of broken items: funeral clothing, personal belongings, reindeer remains, reindeer harnesses, and sledges. Differences between the rich and the poor were expressed primarily through the nature of the ritual activity during and after burial, rather than through the mortuary offerings deposited with the bodies. One material manifestation of status, however, consisted of reindeer antlers annually deposited over burials, which related to reindeer sacrifices performed in memory of the dead. On the burial places of wealthy families, or the graves of renowned shamans, large heaps of up to several hundred sets of antlers were accumulated (Bogoraz 1904-1909).

The structure of social status and the funeral rites among the Maritime Chukchi were similar. The vehicle for social and material differentiation among the Maritime Chukchi was boat ownership. The owner of a boat was also the master of the crew (six to eight men, not necessarily related) during the hunting trips which entitled him to preferential access to the catch, and especially to those parts of the catch which were marketable, such as whalebone (Czaplicka 1914; Bogoraz 1904-1909). By social convention, however, he was limited in his ability to capitalize on his privileges (Bogoraz 1904-1909).

Thus, among both the Reindeer and Maritime Chukchi we can see the operation of ecological and social factors which, while allowing for marked difference in personal wealth, prevent this wealth from being used to institute ranked society.

The mortuary ritual can again be seen to reflect the structure of wealth and status in the living society. The burial rites of these two societies would result in burials where mortuary offerings would correspond, in 
large part, to the age, sex, and personal achievement of the deceased. The differences in grave assemblages would tend to be quantitative rather than qualitative, with a continuum linking poorer members with the richer.

From these we can turn to one of the most complex societies of the Boreal zone in Siberia, the Yakut. The Yakut were originally steppe dwellers who moved to the middle reaches of the Lena in the eleventhtwelfth century (Okladnikov 1970), and as such their social structure may be a relict from their previous adaptation. The Yakut possessed a stratified society, headed by toyons or hereditary clan leaders who represented the elite of Yakut society. Wealth differences in Yakut society reflected the stratified social order, including several terms to denote an individual's wealth status: hereditary rich men, men with large and firmly based economies, middlings, and poormen (Okladnikov 1970).

Burial treatment in Yakut society also reflected the stratified social system. A toyon was buried not only with his personal possessions, weapons, and garments, but also with his horse and saddle. Frequently a servant or a wife was also buried with the man. Poorer Yakut were obviously not accorded such burial. In addition to toyon, privileged positions in Yakut society which also were differentiated in the funerary treatment included the shaman and blacksmith.

As the Yakut were principally horse and cattle breeders with their tribal structure being derived in part under the conditions of steppe life, they are not completely representative of a society living in the forested Boreal environment. However, they emphasize the fact that in the Boreal zone, as elsewhere (Binford 1971), it is the structure and complexity of the living society which are expressed in the organization of their mortuary practices.

In terms of the basic economy, Oleneostrovski society might correspond best with the recent hunters and fishers of the interior of Boreal Siberia, such as the Yukagir or the Khantsy. Neither of these two peoples developed any persistent form of social differentiation (Czaplicka 1914; Jochelson 1926), and the differences in personal wealth which did exist were minimal (Jochelson 1926). Only among the shaman do we observe marked differences in mortuary treatment, which otherwise reflected only the age, sex, and personal activities of the deceased (Jochelson 1926; Balzer 1980).

Yet, in terms of status differentiation and social complexity, the Khantsy and the Yukagir seem to be organized at a considerably lower level than that indicated in the burial remains from Oleneostrovski society. This may well suggest that although the basic ecological conditions were similar, the economic organization of the societies and indeed their social environments were markedly different. As such it may well be that the cultural climax of human occupation in the Boreal zone may indeed 
be found during late Mesolithic times, with a maximum density of occupation and maximum social complexity, and that more recent hunterfisher-gatherer occupations represent only a pale reflection of this peak.

\section{DEMOGRAPHIC ANALYSIS}

Two approaches are available for the study of past population size and dynamics: the analysis of skeletal materials to ascertain population structure, and the analysis of human/ecological relationships to estimate population size and density. First we will present a tentative reconstruction of the Oleneostrovski population from the osteological remains; this will be followed by a preliminary estimate of the region's population ecology.

From the 170 excavated graves at Oleneostrovski mogilnik, age estimates were possible for 116 individuals and sex determinations for 102 individuals. Due to the poor state of bone preservation at the site, precise determinations of age could not be made. Instead individuals were placed into relatively coarse age brackets. For the purpose of the present analysis, these age brackets have been subdivided into 5-year intervals, and individuals within each age bracket were allocated in an even manner across these 5-year age intervals (following Acsádi and Nemeskéri 1970).

An initial examination of the population is sufficient to detemine that the Oleneostrovski remains do not represent a natural population, but rather reflect one with a strong bias against the representation of subadults. Individuals under the age of 10 years make up only $7 \%$ of the Oleneostrovski population, when in natural populations the expectation would be anywhere from 30 to $50 \%$ (Weiss 1973). Preservation of the less robust infant bones is clearly one factor in this underrepresentation, but the absence of the expected "empty" graves and the overwhelming number of missing infants argue that the primary cause for the missing subadults is the differential mortuary treatment of this age group by the Oleneostrovski society.

To reconstruct the parameters of a past population from a skeletal series, it is necessary to assume that the sample is complete, or at least representative of the dead produced by the living society (O'Shea 1978). Therefore, if we are to make an estimate from the Oleneostrovski series we must correct the values to offset the distortion produced by the differential burial of the dead. By enhancing the number of subadults by an additional 18 individuals, we bring their total up to $20 \%$ of the overall population. This figure may still be too low, but it does provide a basis from which an initial estimate of the Oleneostrovski population parameters can be made.

With this correction, an abridged life table (Table 3) was constructed for the combined population (Acsádi and Nemeskéri 1970), assuming a stationary population (one in which there is no net growth as mortality 
TABLE 3

OLENEOSTROVSKI MOGILNIK-ABRIDGED LIFE TABLE

\begin{tabular}{ccrrrr}
\hline Age & $D_{x}$ & $d_{x}$ & $l_{x}$ & $q_{x}$ & $e_{x}^{0}$ \\
\hline $0-4$ & $17.9^{a}$ & 13.4 & 100.0 & 0.1340 & 29.6 \\
$5-9$ & $8.9^{a}$ & 6.6 & 86.7 & 0.0761 & 28.7 \\
$10-14$ & 4.9 & 3.7 & 80.1 & 0.0462 & 25.9 \\
$15-19$ & 10.1 & 7.5 & 76.4 & 0.0820 & 22.0 \\
$20-24$ & 16.1 & 12.0 & 68.9 & 0.1742 & 19.1 \\
$25-29$ & 16.1 & 12.0 & 56.9 & 0.2109 & 17.1 \\
$30-34$ & 10.9 & 8.1 & 44.9 & 0.1804 & 16.7 \\
$35-39$ & 9.6 & 7.2 & 36.8 & 0.1957 & 14.8 \\
$40-44$ & 9.6 & 7.2 & 29.6 & 0.2432 & 12.8 \\
$45-49$ & 9.6 & 7.2 & 22.4 & 0.3214 & 11.2 \\
$50-54$ & 5.6 & 4.2 & 15.2 & 0.2763 & 10.3 \\
$55-59$ & 4.6 & 3.4 & 11.0 & 0.3091 & 8.2 \\
$60-64$ & 4.6 & 3.4 & 7.6 & 0.4474 & 5.8 \\
$65-69$ & 4.6 & 3.4 & 4.2 & 0.8095 & 3.5 \\
$70+$ & 0.9 & 0.8 & 0.8 & - & 2.5 \\
\hline
\end{tabular}

Key. $D_{x}$, number dying age $x ; d_{x}$, proportion dying age $x ; l_{x}$, proportion surviving to age $x ; q_{x}$, probability of death age $x ; e_{x}^{0}$, life expectancy of individual age $x$.

${ }^{a}$ Corrected for subadults, additional 13.7 individuals age $0-4$ and 4.7 individuals age 5-9.

exactly balances natality). The population at Oleneostrovski would have had a life expectancy at birth of 29.6 years (or an equivalent mortality rate of 0.0338 ). The overall sex ratio of the population would have been $132 / 100$ (i.e., 55 males to 44 females), a value which is somewhat skewed toward males. Examining only the adult portion of the life table, we find that 34.7 years is the average age for all adults, with males having a slightly higher, and females a slightly lower, mean age (Table 4). Although the Oleneostrovski sample is not ideal for this type of analysis, the estimated population parameters for the adults are probably quite close to the true values.

Using the basic mortality information from the life table we can model some alternative estimates for the size of the living population and the length of time during which the site was in use.

TABLE 4

Oleneostrovski MOgILNIK-AVERAGe Adult Age

\begin{tabular}{ll}
\hline Category & Years \\
\hline All adults & 34.7 \\
Males & 36.5 \\
Females & 33.2
\end{tabular}


Taking the life expectancy at birth of 29.6 years, and the corrected value for the number of infants, we derive a total population of 220 persons. In addition, it has already been noted that only about one-third of the site has actually been excavated, which might suggest the actual cemetery population to be in the range of 660 individuals. Using this value we can provide estimates for the size of the living population assuming differing numbers of years of site use. We will also contrast the values assuming a year-round occupation of the site and a seasonal occupation with an average duration of half a year (Table 5).

These two models present the limiting alternatives for the occupation type reflected in the formation of the Oleneostrovski mogilnik. The yearround model assumes that the dead for the whole year were interred, while the seasonal model assumes that only individuals who died during the time that the site was occupied were interred at the site.

One other aspect of site use may be relevant here. Two distinct clusters of burials were observed, and it has been suggested that these clusters reflect distinct corporate or social groups. The southern cluster is incomplete due to the location of a quarry on that portion of the site, but the whole of the northern cluster was recovered in the excavations. If these clusters do, indeed, reflect distinct groups, we might profitably use them to estimate the size of this smaller unit of the Oleneostrovski society. Taking the 120 individuals recovered from the northern cluster, and making the correction for missing subadults, we would expect it to comprise a total of 151 individuals. Using this figure we again can model the length of occupation and contrast a year-round with a seasonal occupation of the site area (Table 5).

Taking these figures together, the likely upper and lower limits of the Oleneostrovski population size can be specified. It will be argued in the next section that there is strong evidence for the seasonal occupation of Oleneostrovski, and for this reason our considerations will focus pri-

TABLE 5

Oleneostrovski mogil.nik-Modfi, Popillation Siz.F Rfi.ative to DURATION OF SITE USE

\begin{tabular}{cccccc}
\hline & \multicolumn{2}{c}{ Whole site } & & \multicolumn{2}{c}{ North cluster } \\
\cline { 2 - 3 } \cline { 5 - 6 } Years occupied & Year-round & Seasonal & & Year-round & Seasonal \\
\hline 5 & 3908 & 7816 & & 894 & 1788 \\
10 & 1955 & 3910 & & 447 & 894 \\
25 & 784 & 1568 & & 179 & 358 \\
50 & 396 & 792 & & 90 & 178 \\
100 & 205 & 410 & & 44 & 90 \\
200 & 118 & 236 & & 22 & 44 \\
\hline
\end{tabular}


marily on the seasonal occupation models. From the table, it seems highly unlikely that the site was in use for less than 50 years as populations of this size would be wholly unprecedented for this region, creating as they would large and complex settlements which certainly are not known at the present time in the Onega region. The models for 50, 100, and 200 years fall within the range known for hunter-gatherer-type societies. Assuming that the northern cluster figures represent the size of the stable year-round grouping, the 200-year model would be toward the lower end of ethnographically known cases, and the 50-year model would be toward the upper end.

To differentiate between the 50-, 100-, and 200-year occupation models we need to examine other classes of evidence from Oleneostrovski mogilnik. One course is to study the social statuses already discussed, and use them to determine the number of generations which are represented in the cemetery. Two prime possibilities of such investigation are the "shaman" burials and the burials of individuals with effigy objects, since there would have been only one or two holders of these social statuses at any given time.

If we consider the shaman burials, we have four individuals, one juvenile, one adult, and two mature individuals. If we assign these individuals ages of 16,30 , and 45 years, respectively, and add these ages together, it produces a total of 136 years. Such a calculation allows for no overlap between these individuals which clearly is unreasonable, but if we follow the 100-year model, this would allow a total of 36 years of overlap for these individuals, a situation which would be reasonable for the transmission of such an office.

If we consider individuals buried with effigy figures, we note six with elk and four with human or snake effigies. If one individual per generation was buried with such symbols, and each generation was approximately 20 years, this would also suggest a time span of 80 to 120 years. (This lower estimate may be affected by postdepositional distortion due to quarrying activities in the southern cluster.) Since both of these tests produce results in the range of 100 years, it seems that the 100-year occupation is supported over the other two alternatives.

It is also possible to test the population size and site occupation estimates against local environmental data and ethnographic models of hunter-gatherer population dynamics. Wobst (1974) in his model of $\mathrm{Pa}$ leolithic bands makes the point that local breeding populations must exceed 175 persons if a population is to be a viable and continuing entity. Clearly, this factor on its own does not preclude the population using Oleneostrovski from being smaller than this figure, given the intensity of human occupation in the Lake Onega region. The very density of occupation and the complexity of the Oleneostrovski burial practices may, 
however, argue that boundary maintenance among these societies was an important consideration. If this were true, we would expect the local population at the Oleneostrovski mogilnik to meet Wobst's minimum size. Referring to Table 5 we note that either the 100 - or 200 -year seasonal occupation model would satisfy this requirement while the 50-year model is well above this level. Furthermore, taking the burial clusters as relatively autonomous groupings, they (based on the figures from the north cluster, Fig. 2) would meet the population size criterion assuming a 50year, seasonal occupation.

The evidence available for estimating the size and the duration of the Oleneostrovski mogilnik use is summarized in Table 6.

These indicators all suggest that the population using the site was relatively large by the standards of nonagriculturalists, and that the occupation was relatively brief, probably representing between 80 and 120 years. This then suggests that we are dealing with a population of about 500 people, which was internally subdivided into several bands, each numbering about 90 persons. Using these figures it may also be possible to speculate as to the territory utilized by the Oleneostrovski population.

The ethnographic literature on hunter-gatherers provides very broad limits for the territory sizes necessary in such adaptations, rarging from more than $100 \mathrm{~km}^{2} /$ person in poor habitats to $3 \mathrm{~km}^{2} /$ person in rich lacustrine and riverine environments (Dolgikh 1960). In the region adjacent to Karelia, in southern Finland, Zvelebil (1981) determined an ecologically based population maximum of $5 \mathrm{~km}^{2} /$ person.

Considering that Oleneostrovski mogilnik is located in the lacustrine zone rich in food resources (see below), the population density can be expected to approach the higher figures. Accepting therefore $5 \mathrm{~km}^{2}$ / person as the best approximation of the population density of the area, the territory of the group(s) using the Oleneostrovski burial grounds would be some $2500 \mathrm{~km}^{2}$. Such an area agrees well with the distribution of sites in the Oleneostrovski area (local group 1, as defined by Pankrushev 1978).

TABLE 6

Summary of EVIDENCE RELATING to THE Size AND DURATION OF USE OF OLENEOSTROVSKI MOGILNIK

\begin{tabular}{ll}
\hline Class of evidence & \multicolumn{1}{c}{ Conclusion } \\
\hline Environmental & Seasonal occupation \\
Biological & $50-100$ years \\
Mortuary symbolism & $80-120$ years \\
Social complexity & Relatively large composite population \\
Social environment & Complex interaction ${ }^{a}$ \\
\hline
\end{tabular}

a See the section, Oleneostrovski mogilnik in The Regional Setting. 


\section{OLENEOSTROVSKI MOGILNIK IN THE REGIONAL SETTING}

In a broad economic perspective, Oleneostrovski is located in one of the most productive ecotones of the Boreal zone: along the shore of a large lake, that is to say an area whic i tends to have the highest terrestrial and aquatic biomass concentrations in the northern latitudes (Zvelebil 1981). The biomass concentrations and their potential food value to human populations peak in the late spring and during the summer with the passage of migratory fowl fish runs, and congregations of elk to feed on the aquatic plants along the shores of the lake. Work carried out by Zvelebil (1981) in the related context of Finland suggests that during these seasons, large human aggregations, numbering several hundred people, could be sustained on such resources. This agrees with the general hunter-fisher resource use pattern observed elsewhere in the Boreal zone (cf. Rogers 1962; Jorhim 1976; Eidlitz 1969), which is characterized by seasonal aggregations along large rivers and lakes during the summer part of the year and by dispersal in the autumn and winter for ungulate hunting and trapping.

There are both biological and archaeological arguments favoring the view that the interments at Olencostrovski took placc during the summer half of the year, in connection with the gathering together of people along the lake shores. Even today, Lake Onega is among the most productive lakes in the region, and Gurina (1956) quotes an opinion that the same species of fish were present in the lake during the Neolithic period as exist today. At the present time, fish runs and spawning extend without interruption from the end of April until mid-June and then occur again late in September, including several species of salmon, pike, and fish of the carp family. These are also the times of the greatest concentrations of fowl. In addition to the perforated tooth pendants, osteological material found at Oleneostrovski mogilnik include bones of reindeer, elk, beaver, wolf, bear, dog, and numerous birds. Although no fishbones were preserved, sinkers, composite fishhooks, bone hooks, and harpoons found among the burial goods at the cemetery show that the fishing potential of the lake was exploited in numerous ways.

Finally if we accept the principle that the deceased were buried facing the rising sun (Gurina 1956), the direction of the burials is consistent with spring, summer, and early autumn. Moreover, the use of the Oleneostrovski cemetery during the winter months would be unlikely for two reasons: (1) the difficulty of excavating a grave in the frozen and snowbound ground; and (2) the low concentration of food resources available in the area brought about by the absence of waterfowl and the dispersal of deer resources.

These considerations lead us to reconstruct the Oleneostrovski settle- 
ment-subsistence pattern, at least tentatively, as a dispersed and mobile one during the late autumn and winter, and an agglomerated and more sedentary one during the summer half of the year. Oleneostrovski mogilnik would not have been used during the winter when people broke up into small groups for ungulate hunting and trapping away from the lake. Individuals who died during this period might have been preserved in the cold conditions and perhaps were selectively brought back for burial at the cemetery in the spring.

In the summer, people would concentrate along the lake to take advantage of the seasonally abundant resources and to engage in a broad range of social activities. Oleneostrovski mogilnik may have served as a focal point for such activities if, as the mortuary analysis suggests, more than one social segment made use of the cemetery.

To understand the region's social environment and the relations among the peoples living in the vicinity of Oleneostrovski, we must consider and contrast the artifact assemblages of other sites in the region. The artifact inventory of the Oleneostrovski mogilnik is incomparably richer than that of other sites in the area (Table 7). First, the mortuary artifacts consisted of a wide range of finished and valuable objects which rarely occur on dwelling sites, where as a rule we find only broken fragments, unfinished pieces, or rejects. The typological identity of such finds often cannot even be established. Second, Oleneostrovski mogilnik contained only a few traces of any manufacturing activity, whereas cores, flakes, and debitage form a substantial portion of archaeological assemblages elsewhere. Third, good preservation conditions at the mogilnik ensured the preservation of the bone fraction of the assemblage, a situation that has not yet been observed on the dwelling sites of the area.

These factors have created considerable difficulty in matching the Oleneostrovski assemblage with other sites in the region, but it does enable us to make some interesting observations: (1) finds from the dwelling sites are but a pale reflection of the actual richness and variety of the material culture of late Mesolithic society (see Table 7); (2) the high quality and value of the finds in the cemetery but absent from the dwelling sites underlie their significance as objects of status and ritual; (3) most of the objects found at Oleneostrovski were manufactured elsewhere.

Pankrushev (1978) has defined two separate industries in the late Mesolithic of Karelia; an indigenous quartz- and slate-working industry, and a flint-based industry which he considers intrusive to the area and bearing similarities to the flint assemblages of the upper Volga region.

This situation is reflected in the region of north Onega, where Oleneostrovski mogilnik is located. We have two groups of sites in the area: an indigenous group making use of local quartz and slate materials, and an intrusive group, apparently related to the people of the flint-producing 
TABLE 7

Artifact Assemblage of Oleneostrovski mogilnik Compared With Seven Flint-Dominated Sites IN THE Region ${ }^{a}$

\begin{tabular}{lcc}
\hline & $\begin{array}{c}\text { Oleneostrovski } \\
\text { mogilnik }\end{array}$ & $\begin{array}{c}\text { Other flint- } \\
\text { dominated sites }\end{array}$ \\
\hline Projectiles (bone and stone) & 337 & 13 \\
Daggers & 6 & 0 \\
Harpoons & 6 & 0 \\
Fishhooks & 9 & 0 \\
Sinkers & $14^{b}$ & 4 \\
Slate knives & 60 & 3 \\
Flint knives & 13 & 5 \\
Abraders and sharpeners & 8 & 65 \\
Saws & 0 & 6 \\
Retouchers & 0 & 8 \\
Axes, adzes, and chisels & 5 & 103 \\
Scrapers & 0 & 295 \\
Burins & 0 & 35 \\
Polishers & 7 & 1 \\
Flint blades & 56 & 414 \\
Awls (bone) & 14 & 1 \\
Needles (bone) & 4 & 0 \\
Bear tusks & 127 & 0 \\
Elk incisor pendants & $4273^{c}$ & 0 \\
Beaver incisor pendants & 1201 & 0 \\
Other bone/stone pendants & 142 & 0 \\
Engraved ornaments & 31 & 0 \\
Snake effigies & 1 & 0 \\
Elk effigies & 7 & 0 \\
Human effigies & 3 & 06 \\
Flakes & 24 & $\mathrm{~m}^{2}$ \\
Preforms & $14^{b}$ & \\
Area excavated & $2350 \mathrm{~m}$ & 0 \\
\hline After Gurina (1956) & & 0 \\
\hline
\end{tabular}

${ }^{a}$ After Gurina (1956) and Pankrushev (1978).

${ }^{b}$ Some of the trimmed pieces of stone and fragments of slate plates may have been used as sinkers; however, their function is uncertain.

${ }^{c}$ Gurina (1956) indicates 4273 elk incisors found. Pankrushev (1978) states that 6879 were found. This may reflect the results of excavations in the intervening 22 years. In general, we follow Gurina (1956), which is, to our knowledge, the last comprehensive account of excavations at Oleneostrovski mogilnik.

areas to the east of Onega (Fig. 1). With flint rather than quartz as the principal raw material, Oleneostrovski mogilnik belongs to the flint-using group, although many of its prestige items, such as the slate knives, were probably obtained through trade with the local quartz-using groups. Indeed, we would like to suggest that the wealth evident from the mortuary finds at the Oleneostrovski mogilnik is at least partly due to the role of 
the deceased as middlemen in the flint and slate exchange between the flint- and slate-producing regions (Fig. 1).

In the late Mesolithic of Karelia, Pankrushev (1978) distinguished five spatially separate groups, distinct in their tool-kit composition and in their use of stone media (Tables 8,9$)$. With respect to the manufacture and distribution of flint and slate tools, we can make the following observations.

In general, quartz/slate groups contain a greater number of stone- and woodworking implements, while the flint industry sites have a greater quantity of cutting tools. The difference in cutting tools can be explained by the different stone media used by the two industries: cutting and scraping element of the flint assemblages is characterized by flint tools with sharp, straight edges, while scrapers predominate in the quartz industry. The cutting and flaying needs of the quartz/slate groups were augmented by tools of slate and bone, which in a fragmented state could not be recognized functionally, or, in the case of bone, would perish altogether.

TABLE 8

Assemblage Composition in the Oleneostrovski Area Compared with Other Areas IN KARELIA ${ }^{a}$ - TOOL-TYPE CATEgORIES

\begin{tabular}{|c|c|c|c|c|c|c|c|c|}
\hline \multirow[b]{3}{*}{ Tool kit composition } & \multicolumn{4}{|c|}{$\begin{array}{l}\text { Oleneostrovski area } \\
\text { (local group 1) }\end{array}$} & \multicolumn{4}{|c|}{$\begin{array}{l}\text { Other parts of Karelia } \\
\text { (groups 2, 4, 5-quartz) } \\
\text { (group 3-flint) }\end{array}$} \\
\hline & \multicolumn{2}{|c|}{$\begin{array}{c}\text { Flint } \\
n=4\end{array}$} & \multicolumn{2}{|c|}{$\begin{array}{l}\text { Quartz } \\
n=10\end{array}$} & \multicolumn{2}{|c|}{$\begin{array}{l}\text { Flint } \\
n=4\end{array}$} & \multicolumn{2}{|c|}{$\begin{array}{l}\text { Quartz } \\
n=48\end{array}$} \\
\hline & Freq. & $\%$ & Freq. & $\%$ & Freq. & $\%$ & Freq. & $\%$ \\
\hline $\begin{array}{l}\text { Chopping, felling, and wood } \\
\text { working tools (axes, adzes, } \\
\text { chisels, and celts) }\end{array}$ & 15 & 3.9 & 390 & 51.6 & 113 & 10.6 & 208 & 17.0 \\
\hline $\begin{array}{l}\text { Stone working tools } \\
\text { (abraders, sharpeners, } \\
\text { saws retouchers) }\end{array}$ & 19 & 5.0 & 172 & 22.8 & 81 & 7.6 & 175 & 14.3 \\
\hline $\begin{array}{l}\text { Hunting and fishing } \\
\text { (projectiles, sinkers, } \\
\text { and fishhooks) }\end{array}$ & 127 & 33.1 & 28 & 3.7 & 22 & 2.0 & 8 & 0.7 \\
\hline Scrapers and burins & 37 & 9.7 & 88 & 11.6 & 269 & 25.2 & 655 & 53.4 \\
\hline $\begin{array}{l}\text { Cutting tools (knives, } \\
\text { blades, and retouched } \\
\text { insets) }\end{array}$ & 152 & 40.0 & 74 & 9.7 & 576 & 54.0 & 173 & 14.8 \\
\hline $\begin{array}{l}\text { Household items (awls, } \\
\text { needles, polishers) }\end{array}$ & 33 & 8.6 & 4 & 0.5 & 5 & 0.5 & 9 & 0.7 \\
\hline Total & 383 & & 756 & & 1066 & & 1128 & \\
\hline
\end{tabular}

${ }^{a}$ After Pankrushev (1978). 
TABLE 9

Assemblage Composition in the Oleneostrovski Area Compared with Other AReas in Karelia ${ }^{a}$ - Raw Material Categories

\begin{tabular}{|c|c|c|c|c|c|c|c|c|}
\hline \multirow{3}{*}{$\begin{array}{l}\text { Raw material } \\
\text { composition }\end{array}$} & \multicolumn{4}{|c|}{$\begin{array}{l}\text { Oleneostrovski area } \\
\text { (local group 1) }\end{array}$} & \multicolumn{4}{|c|}{$\begin{array}{l}\text { Other parts of Karelia } \\
\text { (groups } 2,4,5 \text {-quartz) } \\
\text { (group 3-flint) }\end{array}$} \\
\hline & \multicolumn{2}{|c|}{$\begin{array}{c}\text { Flint } \\
n=4\end{array}$} & \multicolumn{2}{|c|}{$\begin{array}{l}\text { Quartz } \\
n=10\end{array}$} & \multicolumn{2}{|c|}{$\begin{array}{c}\text { Flint } \\
n=4\end{array}$} & \multicolumn{2}{|c|}{$\begin{array}{l}\text { Quartz } \\
n=48\end{array}$} \\
\hline & Freq. & $\%$ & Freq. & $\%$ & Freq. & $\%$ & Freq. & $\%$ \\
\hline \multicolumn{9}{|l|}{ Tools } \\
\hline Quartz & 12 & 3.3 & 54 & 6.9 & 37 & 3.4 & 891 & 74.4 \\
\hline Slate & 122 & 33.4 & 468 & 60.0 & 144 & 13.2 & 190 & 15.8 \\
\hline Flint & 244 & 61.4 & 90 & 11.5 & 852 & 78.2 & 28 & 2.3 \\
\hline Sandstone & 1 & 0.3 & 131 & 16.8 & 12 & 1.1 & 15 & 1.3 \\
\hline Other & 6 & 1.6 & 37 & 4.7 & 44 & 4.0 & 73 & 6.0 \\
\hline Total & 365 & & 780 & & 1089 & & 1197 & \\
\hline \multicolumn{9}{|l|}{ Debris } \\
\hline Quartz & 127 & 26.2 & 946 & 33.0 & 492 & 11.8 & 7636 & 96.0 \\
\hline Slate & 188 & 38.8 & 1449 & 50.5 & 603 & 14.5 & 286 & 3.6 \\
\hline Flint & 135 & 27.9 & 472 & 16.5 & 3056 & 73.6 & 28 & 0.3 \\
\hline Sandstone & 34 & 7.0 & 0 & & 0 & & 0 & \\
\hline Total & 484 & & 2867 & & 4157 & & 7950 & \\
\hline
\end{tabular}

${ }^{a}$ After Pankrushev (1978).

But this does not explain the greater quantities of axes, adzes, chisels, wedges, saws, polishers, and other wood- and stoneworking tools in the quartz/slate industry. Two points are worth noting in this regard: (1) most of these tools are made of slate, and (2) it is the sites in the region of Oleneostrovski which have large proportions of these slate tools in their assemblages. In this particular region, about $60 \%$ of all artifacts were made of slate. Moreover, there is evidence of intensive slate tool production: slate forms $50 \%$ of the debris found at these sites, while the normal range of slate debris in quartz industry ranges between 2 and $7 \%$ $($ mean $=3.6 \%)($ Pankrushev 1978) $($ Tables 8, 9).

A large proportion of the tools used in slate polishing and grinding are made of sandstone (Semenov 1964). Sandstone polishers and grinders and other tool-making implements make up $17 \%$ of the assemblages of the quartz/slate industry sites around northern Lake Onega, while in quartz industry sites in other regions they make up only between 1 and $2 \%$ of the assemblage (Tables 8,9 ). From these observations we may conclude that the inhabitants of the quartz industry sites in northern Lake Onega were engaged in the production of slate tools, and that it is principally these sites which are responsible for the greater proportion of 
slate tools among the quartz industry assemblages in general. The important role played by slate implements in the northern Lake Onega region is also noted by Pankrushev (1978).

This situation is not surprising in view of the distribution of slate sources in the area (Fig. 1). The northwestern shores of Onega contain high quality slate, the best of which is the green slate found in the vicinity of the town of Olonets. Artifacts made of Olonets slate were widely traded in the late Mesolithic and Neolithic periods, and are found in Finland, the Baltic Republics, and northern Russia (Gurina 1956, 1973). The elegant form, the high degree of polish, and the absence of any traces of wear on some of these artifacts suggest that they possessed a ritual rather than functional significance, marking authority, wealth, or other expressions of social status. This use was well illustrated in the mortuary symbolism at Oleneostrovski mogilnik.

Such fine artifacts are rarely, if ever, found in the functional contexts of dwelling sites. Slate artifacts found at these sites consist mainly (85\%) of semifinished or broken implements (Pankrushev 1978), and are of a clearly functional character such as axes, adzes, and chisels. On the other hand, highly finished artifacts, or objects whose shape or size precludes a functional use, are found in ritual or burial contexts. Of the 63 slate knives known from Karelia, 60 were found in burials at Oleneostrovski mogilnik, while only 3 were found on dwelling sites.

It was noted earlier that Oleneostrovski belongs among the sites exhibiting a flint-based industry. Settlements with flint industries have remarkably few implements related to slate manufacture (about 5\%), or indeed for the manufacture of any kind of stone tool. This would point to two conclusions: (1) slate knives and other slate artifacts, such as those interred at Oleneostrovski, were procured from the makers of the quartz industry; and (2) flint artifacts common on the sites of the flint industry groups were brought into the area of northern Onega in a finished or semifinished state.

Again, this situation is not surprising in view of the overall distribution of flint in the region. Flint is not found in Karelia, and the nearest sources are located in coal seams extending from the Valdai uplands to the White sea (Fig. 1) (Gurina 1973). This explains the low frequency of flint debris on sites in the vicinity of Oleneostrovski, while similar flint-industry sites across Lake Onega and along its southern shore (which are thus closer to the flint sources) yield greater quantities of flint debitage (Pankrushev 1978). Moreover, from the high degree of typological similarity of flint artifacts of the two groups (Pankrushev 1978) it seems reasonable to assume that the flint objects found in the quartz industry were obtained from the flint-using groups.

Given this pattern of distribution and consumption of flint tools, it 
seems probable that the flint-using sites in the vicinity of Oleneostrovski mogilnik served as trading stations in the exchange of flint in the area. If true, this could further indicate some kind of long-standing trade relation with the flint-producing sites south of Lake Onega, confirming the assertions made on the basis of flint tool typology (Pankrushev 1978).

The picture which emerges from this discussion is one of considerable movement and exchange of artifacts within the region. Slate tools, manufactured from local sources on the northwest shores of Lake Onega, were distributed throughout southern Karelia, eastern Finland, and northern Russia. In exchange, the local groups obtained their supply of flint tools from the northern Russian sources.

The possibility that the people buried at Oleneostrovski mogilnik acted as middlemen in the exchange of finished flint and slate objects is tantalizing and could explain, in part, the unprecedented richness of the cemetery. Yet, despite the appeal of Pankrushev's territorial model, alternative explanations for the regional distribution of flint- and quartzusing industries around Lake Onega must be considered. For example, both industries might represent only the spatially or seasonally distinct activities of but a single cultural entity. Indeed, until burials comparable to Oleneostrovski mogilnik are discovered in these other territories, we cannot fully assess the character of regional interaction around Lake Onega nor know the larger social significance of a site such as Oleneostrovski mogilnik.

\section{CONCLUSIONS}

The results of the present analysis, taken together, offer a new and somewhat surprising picture of late Mesolithic society in the Boreal zone. The results indicate that Oleneostrovski mogilnik was produced by a relatively large and stable population. It was a society with considerably internal differentiation, which included not only hereditary social positions, but also a complex economic system reflecting the incipient development of an institutionalized system of social inequality (see also Halstead and O'Shea 1982; O'Shea 1981b). It has also been shown that Oleneostrovski society existed within a complex social environment in which an active regional exchange network moved a wide variety of raw materials and exotic goods. It seems likely that the people of Oleneostrovski mogilnik manipulated this trade.

By comparison, the modern Boreal zone cultures of Siberia seem relatively simple (with the exception of the Yakuts). Far from resembling these, the most convincing ethnographic parallel to Oleneostrovski society, and indeed to the late Mesolithic period in Karelia as a whole, might well be the complex cultures of the American Northwest Coast. 
The broader implications arising from our present findings are threefold. First, the relatively complex social and economic organization of the kind observed at Oleneostrovski mogilnik has an adaptive value. This is especially the case for hunter-gatherers in the Boreal zone. By creating an extensive contact network, the Oleneostrovski mode of social organization fostered exchange and redistribution of information and resources, and promoted a mating network in an environment characterized by extremely low population density and unpredictable resource variations. Indeed, it is a familiar argument that one function of status objects in a primitive exchange system was to balance the distribution of food and other resources (Sahlins 1974; Halsted and O'Shea 1982). The hierarchically ranked valuables at Oleneostrovski mogilnik probably served the same purpose.

The stability of such a socioeconomic system is implied in the extent and duration of the cultural tradition to which Oleneostrovski mogilnik belongs. One of the characteristic aspects of this tradition is the status objects with animal motifs, such as the elk effigies found at Oleneostrovski mogilnik, which may serve as markers of social complexity in the material culture. Carpelan's $(1974,1975)$ analysis of these objects shows that their use extended across Scandinavia, northeast Europe, and western Siberia. The duration of their use spans 5000 years from the sixth millennium B.C. to 1000 B.C. Other aspects of material culture, such as the hunting and fishing gear, household goods, and, from ca. 4000 B.C., pottery, match the sculpted pieces in their diversity of form and design. Overall, this cultural tradition is characterized by the continuation of the hunting-fishing mode of life and by gradual economic intensification (Zvelebil 1980). After about 1000 B.C. we observe a slow decline in the material culture and a transition to less stable modes of subsistence: reindeer husbandry and farming (Zvelebil 1980, 1981).

This brings us to the second point. The cultural impoverishment, evident in the material culture of the foraging societies during the first millennium B.C. suggests that, insofar as forager culture is concerned, we might be dealing with cultural regression. Those groups that continued to hunt into more recent times did so in restricted areas unfit for farming or animal husbandry and their material culture suffered under the adverse social and environmental conditions.

It follows, therefore, that we might be dealing with a hunting-gathering culture more complex in its earlier rather than later stages. This introduces our final point. The unexpected level of social complexity revealed in a prehistoric foraging society 6000 years old demonstrates that the present ethnographic sample, biased as it is toward societies with simple social organization, cannot be representative of the prehistoric past. Even though the biased nature of this sample has been emphasized time and 
again (Lee and DeVore 1968, Levi-Strauss 1968; Sahlins 1974), the "Paleolithic disenfranchised" model of hunting-gathering society has been used in the analysis and explanation of past hunters and gatherers so often (Deevy 1960; Cohen 1977; Hassan 1975, 1978; Tilley 1981; etc.) as to virtually preclude the possible existence of social complexity among prehistoric foragers. Our analysis of the Oleneostrovski society suggests that this view is in error. And indeed, there is no reason to suppose that Oleneostrovski represents a special case. Research in both anthropology and sociology has repeatedly demonstrated the importance of group size and size-related phenomena, such as scalar stress (Johnson 1982) and complexity (Blau 1970), to the overall structuring of any organization, be it a hunter-gatherer band or a multinational corporation. This would suggest that the key variable for understanding differentiation and complexity in the past is the size of the regularly interacting residential units. Complexity and differentiation, therefore, are not the necessary concomitant of any specific subsistence type, but rather reflect the density of population which a given subsistence system could support in a particular environmental setting.

Thus, we may expect to observe a broad range of social forms associated with prehistoric hunter-gatherer adaptations which reflect the diversity of environments in which such adaptations were at one time practiced. Indeed, we must accept that, in the past, man the hunter was capable of creating a society organized on the basis of economic ranking and inequality. The "noble savage" did not always live in an egalitarian paradise.

\section{REFERENCES CITED}

Acsádi, Gy., and J. Nemeskéri

1970 History of human life span and mortality. Akadémiai Kiad6, Budapest.

Albrethsen, S., and E. Peterson

1976 Excavation of a Mesolithic cemetery at Vadbaek, Denmark. Acta Archaeologica 47:1-28.

Balzer, M. M.

1980 The route to eternity: Cultural persistence and change in Siberian Khantsy burial ritual. Arctic Anthropology 27:77-89.

Binford, L.

1971 Mortuary practices: Their study and potential. In Approaches to the social dimensions of mortuary practices, edited by J. Brown. Memoir of the Society for American Archaeology 25:6-29.

Black, L.

1972 The Nivkhi of Sakhalin and the Lower Amur. Artic Anthropology 10:1-111.

Blau, P.

1970 A formal theory of differentiation in organizations. American Sociological Review 35:201-218. 
Bogaraz, W.

$1904-$

1909 The Chukchee. Memoir of the American Museum of Natural History 11.

Braun, D.

1979 Illinois Hopewell burial practices and social organization: reexamination of the Klunk-Gibson mound group. In Hopewell archaeology, the Chillicothe conference, edited by D. Brose and N. Greber, pp. 66-79. Kent State Univ. Press, Kent, Ohio.

Brown, J. A.

1971 The dimensions of status in the burials at Spiro. In Approaches to the social dimensions of mortuary practices, edited by J. Brown. Memoir of the Society Carpelan, $\mathrm{C}$. for American Archaeology 25:92-112.

1974 Hirven- ja karhunpääesineitä Skandinaviasta Uralille. Suomen Museo 81:29_ 88.

1975 Älg- och björnhúvudföremål från Europas nordliga delar. Finskt Museum 82:567.

Clarke, D. L.

1976 Mesolithic Europe: the economic basis. In Problems in economic and social archaeology, edited by G. Sieveking, I. Longworth, and K. Wilson, pp. 449481. Duckworth, London.

Cohen, $\mathbf{M}$.

1977 The food crisis in prehistory. Yale Univ. Press, New Haven.

Czaplicka, M.

1914 Aboriginal Siberia. A study in social anthropology. Oxford Univ. Press (Clarendon), London/New York.

Deevy, E.

1960 The human population. Scientific American 203(3):194-204.

Dolgikh, $\mathrm{B}$.

1960 Rodovoi i plemennoi sostav narodov Sibiri v XVII veke, Trudy Instituta Etnographii AN SSSR, Nov. Ser. 55.

Dolukhanov, P.

1979 Ecology and economy in Neolithic Eastern Europe. Duckworth, London.

Dylis, N., and V. Sukhachev

1964 The fundamentals of forest biogeocoenology. Oliver \& Boyd, Edinburgh.

Eidlitz, K.

1969 Food and emergency food in the circumpolar area. Studia Ethnographica Uppsaliensis 32.

Engels, F.

1884 Der Ursprung der Familie, des Privateigentums und des Staates. Zurich (publisher unknown).

Everitt, B.

1974 Cluster analysis. Heinemann, London.

Forsten. A.

1972 The refuse fauna of Mesolithic Suomusjarvi period in Finland. Finskt Museum 79:74-85.

Godelier, M.

1977 Perspectives in Marxist anthropology. Cambridge Univ. Press, Cambridge. Gurina, N.

1956 Oleneostrovski mogilnik. Materialy i issledovaniya po arkheologgi SSSR 47.

1973 K voprosu ob obmene v neoliticheskuyu epokhu. Kratkie soobshchenie instituta materialnoi kultury SSSR (KSIIMK) 138. 
Halstead, P., and J. O'Shea

1982 A friend in need is a friend indeed: social storage and the origins of social ranking. In Ranking resource and exchange: aspects of the archaeology of early European society, edited by C. Renfrew and S. Shennan, pp. 92-99. Cambridge Univ. Press, Cambridge.

Hassan, F.

1975 Determination of the size, density and growth rate of hunting-gathering populations. In Population, ecology and social evolution, edited by S. Polgar, pp. 27-52. Mouton, The Hague.

1978 Demographic archaeology. In Advances in archaeological method and theory, Vol. 1, edited by M. Schiffer, pp. 49-103. Academic Press, New York.

Jochelson, V.

1905-

1908 The Koryak. Memoir of the American Museum of Natural History 10(2).

1926 The Yukagir and the Yukagirized Tunguz. Memoir of the American Museum of Natural History 13.

Jochim, M.

1976 Hunter-gatherer subsistence and settlement: a predictive model. Academic Press, New York.

Johnson, G. A.

1982 Organizational structure and scalar stress. In Theory and explanation in archaeology, edited by C. Renfrew, M. Rowlands, and B. Segraves, pp. 389-421. Academic Press, New York.

Lee, $\mathbf{R}$, and I. DeVore

1968 Problems in the study of hunters and gatherers. In Man the hunter, edited by R. Lee and I. DeVore, pp. 3-12. Aldine, Chicago.

Leeds, A.

1965 Reindeer herding and Chukchi social institutions. In Man, culture and animals, edited by A. Leeds and A. Vayda, pp. 87-128. Publication No. 78, AAAS, Washington, D.C

Levi-Strauss, C.

1968 The concept of primitiveness. In Man the hunter, edited by R. Lee and I. DeVore, pp. 349-352. Aldine, Chicago.

Magnarella, P.

1972 Koryak religion and society: an anthropological perspective. Arctic Anthropology 9:24-31.

Newell, R., T. Constandse-Westermann, and C. Meiklejohn

1979 The skeletal remains of Mesolithic man in Western Europe: an evaluative catalogue. Journal of Human Evolution 8:1-228.

Okladnikov, A.

1970 Yakutia. McGill-Queens Univ. Press, Montreal.

O'Shea, J.

1978 Mortuary variability; an archaeological investigation with case studies from the nineteenth century Central Plains of North American and the Early Bronze Age of southern Hungary. Unpublished Ph.D. dissertation, Cambridge University.

1981a Social configurations and the archaeological study of mortuary practices: a case study. In The Archaeology of Death, edited by R. Chapman, I. Kinnes, and K. Randsborg, pp. 39-52. Cambridge Univ. Press, Cambridge.

1981b Coping with scarcity: exchange and social storage. In Economic archaeology: towards an integrated approach, edited by A. Sheridan, and G. Bailey, British Archaeological Reports, International Series 96:167-183. 
Pankrushev, G.

1978 Mesolit i neolit Karelii, tom 1: Mesolit. Nauka, Leningrad.

Peebles, C.

1972 Monothetic-divisive analysis of the Moundville burials: an initial report. Newsletter of Computer Archaeology 8:1-13.

Ravdonikas, V.

1940 Neoliticheskii mogilnik na Onezhskom ozere. Sovetskaya Arkheologiya 6.

Rogers, E.

1962 The Round Lake Ojibwa. Royal Ontario Museum Occasional Papers 5.

Sahlins, M.

1974 Stone Age economics. Aldine, Chicago.

Saxe, A.

1970 Social dimensions of mortuary practices. Unpublished Ph.D. dissertation, University of Michigan.

Semenov, S.

1964 Prehistoric technology. Adams \& Dart, Bath.

Siegel, $\mathbf{S}$.

1956 Nonparametric statistics for the behavioral sciences. McGraw-Hill, New York.

Siiriäinen, A.

1973 Studies relating to shoreline displacement and Stone Age chronology in Finland. Finskt Museum 80:5-22.

Sneath, P., and R. Sokal

1973 Numerical taxonomy. Freeman, San Francisco.

Tainter, J.

1975 Social inference and mortuary practices: an experiment in numerical classifi-

Taylor, W. cation. World Archaeology 7:1-15.

1967 A study of archaeology. Southern Illinois Univ. Press, Carbondale.

Tilley, C.

1981 Conceptual frameworks for the exploration of sociocultural change. In Pattern of the past, edited by I. Hoddler, G. Isaac, and N. Hammond, pp. 387-412. Cambridge Univ. Press, Cambridge.

Weiss, $\mathrm{K}$.

1973 Demographic models for anthropology. Society for American Archaeology Memoir 27.

Wishart, D.

1978 Clustan user manual, 3rd ed. Edinburgh University, Edinburgh.

Wobst, $\mathrm{M}$.

1974 Boundary conditions for Paleolithic social systems: a simulation approach. American Antiquity 39:75-81.

1978 The archaeo-ethnology of hunter-gatherers or the tyranny of the ethnographic record in archaeology. American Antiquity 43:303-309.

Zagorski, F.

1973 Das Spätmesolithikum in Lettland. In The Mesolithic in Europe, edited by S. K. Kozlowski, pp. 651-670. The University Press, Warsaw.

Zvelebil, M.

1978 Settlement and subsistence in northeastern Europe. In The early postglacial settlement of Europe, edited by P. Mellers, pp. 205-242. Duckworth, London.

1980 Northern forest cultures and the Arctic fringe. In The Cambridge encyclopedia of archaeology, edited by A. Sherratt, pp. 320-323. Cambridge Univ. Press, Cambridge.

1981 From forager to farmer in the Boreal Zone. British Archaeological Reports, International Series 115. 